\title{
Review Article \\ Type I Interferon at the Interface of Antiviral Immunity and Immune Regulation: The Curious Case of HIV-1
}

\author{
Adriano Boasso \\ Immunology Section, Chelsea and Westminster Hospital, 369 Fulham Road, London SW10 9NH, UK \\ Correspondence should be addressed to Adriano Boasso; a.boasso@imperial.ac.uk
}

Received 12 November 2013; Accepted 10 December 2013

Academic Editors: G. Chen and M. Clementi

Copyright (C) 2013 Adriano Boasso. This is an open access article distributed under the Creative Commons Attribution License, which permits unrestricted use, distribution, and reproduction in any medium, provided the original work is properly cited.

\begin{abstract}
Type I interferon (IFN-I) play a critical role in the innate immune response against viral infections. They actively participate in antiviral immunity by inducing molecular mechanisms of viral restriction and by limiting the spread of the infection, but they also orchestrate the initial phases of the adaptive immune response and influence the quality of $\mathrm{T}$ cell immunity. During infection with the human immunodeficiency virus type 1 (HIV-1), the production of and response to IFN-I may be severely altered by the lymphotropic nature of the virus. In this review I consider the different aspects of virus sensing, IFN-I production, signalling, and effects on target cells, with a particular focus on the alterations observed following HIV-1 infection.
\end{abstract}

\section{Introduction}

Interferons (IFN) are a heterogeneous class of soluble immune mediators which were originally defined by their ability to interfere with the replication of diverse types of viruses in vitro and in vivo. Human type I IFN (IFN-I) include IFN- $\alpha$ (14 genes, resulting in more than 22 products) and IFN- $\beta$, both encoded by genes clustered on chromosome 9 , probably generated as a result of gene duplication events, as epitomized by the presence of multiple pseudogenes [1]. IFN- $\mathcal{E}$, IFN- $\kappa$, IFN- $\tau$, and IFN- $\omega$ have also been described in mammals as members of the IFN-I family. This review is focused on the literature covering the regulation and the function of IFN- $\alpha$ and IFN- $\beta$.

IFN-I are produced in large quantities in response to viral infections and are generally regarded as a key bridging mechanism between innate and adaptive immune responses, exerting both antiviral activity, and immunostimulatory functions, such as promoting antigen-presenting cell maturation and molding $\mathrm{T}$ helper cell responses [2-8]. However, the notion that IFN-I serve only as effector immune mechanisms may need to be revised based on accumulating evidence which highlights the potent immunoregulatory ability of these molecules. During chronic viral infections, the beneficial antiviral and immunostimulatory effects of IFN-I may be overruled by the prolonged stimulation of IFN-I-induced cytostatic and proapoptotic mechanisms.
Infection by the human immunodeficiency virus type 1 (HIV-1) may represent an extreme example of how chronic IFN-I production progressively undermines the development of efficient long-term antiviral immunity $[9,10]$.

Different cells have the potential to produce IFN-I and the mechanism by which viral insults are sensed varies depending on the cell type, as does the potency of the IFN-I-producing response. In the case of HIV-1, most studies have focussed on plasmacytoid dendritic cells (pDC) as the main producers of IFN-I following viral exposure $[9,11,12]$. However, recent evidence indicates that the source and dynamics of IFN-I production may change during the course of infection, and pDC may be replaced by myeloid dendritic cells (mDC) and monocytes/macrophages as the main source of IFN-I during the transition from acute to chronic infection [13].

Based on the molecular mechanisms of viral sensing involved in HIV-1 recognition by different cells (1), the evidence available on IFN-I production by different cell types during the acute and chronic phases of infection (2) and the combination of antiviral and immunomodulatory activity of IFN-I (3), it is possible to speculate that IFN-I may serve different purposes during different stages of chronic infections, and that the dysregulation of IFN-I production during HIV1 infection may contribute to progressive immunodeficiency. 


\section{Viral Sensing by Pattern Recognition Receptors}

Innate sensing of virus-related pathogen associated molecular patterns (PAMP) relies primarily on recognition of viral nucleic acids by toll-like receptors (TLR) in the endosomes of specialised immune cells, or by cytoplasmic sensors widely expressed by different cell types and not restricted to immune cells [14-19].

HIV-1 interacts with and infects cells expressing CD4, which is engaged by the viral envelope glycoprotein gp120. Thus, IFN-I production during HIV-1 infection is mainly sustained by immune cells which are either exposed to or infected by HIV-1.

2.1. Toll Like Receptors. Toll-like receptors are a family of pattern recognition receptors (PRR) preferentially expressed by cells which participate in the innate immune responses against invading pathogens [14-16]. At least four TLR have the potential to sense viral nucleic acids in humans. Signalling via TLR3, TLR7, and TLR8 is triggered by viral RNA, whereas TLR9 recognizes unmethylated CpG-rich DNA sequences $[15,20]$. Although RNA-sensing TLR have the potential to recognize HIV-1, only TLR7-expressing PDC appear to respond promptly to viral exposure. Conversely, the available evidence either excludes or is inconclusive regarding the ability of HIV-1 to directly activate cells expressing TLR8 or TLR3, such as $\mathrm{mDC}$ and $\mathrm{M} \Phi$, but also microglia and astrocytes within the central nervous system [12, 21-23].

The ability of pDC to respond to HIV-1 stimulation appears to be mainly dependent on TLR7 signalling [24], although a role for TLR9 cannot be excluded [12]. The HIV-1 viral cycle includes the formation of a DNA/RNA heterodimer and a double stranded DNA proviral DNA, which represent potential ligands for TLR9 via CpG-rich DNA regions. Partial reverse transcription may occur already in the virion, due to the packaging of complexes formed by reverse transcriptase, viral RNA genome and transfer RNA primer [25-27]. However, the reverse transcription process is completed in the cytoplasmic environment $[25,27]$, secluded from endosomal TLR9. Whether fragment of DNA of viral origin included in the virion engulfed by $\mathrm{pDC}$ and processed via the endosomal pathway can trigger TLR9-mediated responses remains untested.

Engagement of TLR7/9 results in the activation of a complex network of transduction signalling pathways in pDC. The first step required for TLR7/9 signal transduction is the recruitment of the adaptor molecule myeloid differentiation primary-response gene 88 (MyD88), which in turn associates with other adaptor and signalling molecules to form a complex comprised of TNF-receptor-associated factor (TRAF)6, Bruton's tyrosine kinase (BTK), IL-1R-associated kinase (IRAK) 4 and IRAK1 [20, 28, 29]. The signalling complex catalyzes the activation of different intracellular pathways.

The pathway mediated by the interferon regulatory factor (IRF) 7 is directly associated with activation of IFN- $\alpha$ and IFN- $\beta$ genes following nuclear translocation of IRF7 [30]. Signalling through the IRF7 pathway is dependent on the activation of phosphatidylinositol 3-kinase (PI3K)- $\delta$ [31]. IFN- $\alpha / \beta$ secreted during this early phase may act in an autocrine manner through the dimeric type I IFN receptor (IFNAR) and stimulate de novo production of IRF7, further stimulating IFN-I secretion in a potent positive feedback loop of IFN-I production [28]. The IRF7-mediated signalling pathway is therefore responsible for the differentiation of pDC into efficient IFN-I producing cells (IPC). PI3K and IRF7 signalling is not required for the production of tumor necrosis factor (TNF)- $\alpha$, interleukin (IL)-6, and the chemokines CXCL10 and CCL3, which rely on the canonical nuclear factor (NF)- $\kappa$ B pathway (Rel-A: p50 dimer) which in turn requires mitogen-activated protein kinase p38 (p38MAPK) activity [32]. The same pathway is responsible for promoting the expression of the costimulatory molecules CD80 and CD86, which are conditions necessary for the maturation of pDC into fully competent antigen presenting cells (APC) [32]. TLR7/9 engagement also promotes upregulation of the immunoregulatory enzyme indoleamine $(2,3)$ dioxygenase (IDO) in both murine and human pDC [3336]. In murine models, IDO regulation via TLR7/9 occurs following activation of the noncanonical NF- $\kappa \mathrm{B}$ pathway (Rel-B: p52 complex) [37], and non-canonical NF- $\kappa \mathrm{B}$ is also required to support IFN- $\alpha$ production [38].

IRF7 and NF- $\kappa$ B are not simultaneously activated following TLR7/9 engagement, and the pathway which dominates the signalling cascade is determined by the intracellular compartment where TLR7/9 engagement occurs [39].

2.2. Cytoplasmic RNA Sensors. TLR represent powerful mechanisms for viral recognition, but their expression is limited to immune cells and the restriction to endosomal compartment prevents them from detecting viruses which have reached the cytoplasmic environment. Retinoic acid-inducible gene 1 (RIG-I)-like receptors (RLR) are a family of PRR broadly expressed among different human cells, and confer the ability to sense virus-derived RNA within the cytoplasm $[15,17,18]$. RLR include RIG-I, melanoma differentiation factor (MDA)5, and laboratory of genetics and physiology (LGP) 2 protein, all of which are potently upregulated by IFN-I [40]. Studies conducted in transgenic mice suggest that different RLR are critical in the recognition of and IFN-I response against different viruses [18]. However, it remains unclear how RLR distinguish viral RNA from cellular RNA, and therefore trigger IFN-I production only in infected cells. The specificity for exogenous RNA may be dependent on the recognition of secondary structures which are common in viral RNA genomes [18]. RLR signal transduction occurs through binding of the receptor to the mitochondrial adaptor IFN- $\beta$ promoter stimulator (IPS)-1 and formation of a signalling complex leading to the activation of the kinases TNF receptor-associated factor (TRAF)-associated NF- $\kappa \mathrm{B}$ actvator (TANK) binding kinase (TBK)1-IK $\beta$ kinase (IKK) $\varepsilon[40]$. The TBK1-IKK $\varepsilon$ is then responsible for both IFN-I production via IRF3 and IRF7 and for NF-kB activation [40].

Berg and colleagues demonstrated that genomic HIV RNA can trigger inflammatory responses in human peripheral blood mononuclear cells (PBMC) via RIG-I recognition, 
leading to production of the interleukin (IL)-6, TNF- $\alpha$, IFN- $\alpha$, and IFN- $\beta$ [41]. The cellular sources of the proinflammatory cytokines were not investigated in this study. It is plausible that, during HIV-1 infection in vivo, all cells susceptible of infection have the potential to respond to HIV-1 genomic RNA via RIG-I sensing. However, the nature of the responses may differ depending on the target cells, and inflammatory responses may be differentially mediated by $\mathrm{DC}$ and monocyte/macrophages compared to CD4 T lymphocytes.

2.3. Cytoplasmic DNA Sensors. The presence of a RNADNA hybrid during reverse transcription of the HIV-1 RNA genome into dsDNA suggests that cytoplasmic recognition of the proviral DNA may occur before its translocation to the nucleus and integration into the host genome.

The cytosol of eukaryotic cells is rich in enzymes with DNase activity, which prevent accumulation of DNA in the cytoplasm [42]. However, when the preventive measures exerted by cytoplasmic DNases fail, DNA of viral origin may accumulate in the cytoplasm. Double stranded DNA is a potent immune stimulator when present in the cytosol of target cells $[43,44]$, and recent evidence indicates that single-stranded DNA with specific signatures, such as ATrich regions, is also a strong activator of immune responses [45]. Sensing of cytoplasmic DNA triggers a cascade of signal transduction orchestrated by the adaptor molecule stimulator of interferon genes (STING) [46-49], leading to the production of proinflammatory and antiviral cytokines, including IFN-I [48]. STING engages TBK1 to cause IRF3 activation, and the STING-TBK1-IRF3 signaling axis is critical for IFN-I induction by cytosolic DNA [50].

Recent evidence indicates that cytosolic HIV-1-derived dsDNA or RNA/DNA heterodimers may trigger innate immune responses. Gao and colleagues have used both the monocytic cell line THP1 and primary human monocyte-derived macrophages and dendritic cells to show that HIV infection induces the production of cyclic guanosine monophosphateadenosine monophosphate (cGAMP), which binds to and activates STING resulting in the production of IFN-I [51]. The production of IFN- $\beta$ was strictly dependent on reverse transcription, indicating that HIV-1 DNA acts as the initial trigger for IFN-I production [51]. Furthermore, Jakobsen and colleagues have shown that ssDNA generated from HIV-1 proviral genome is a potent activator of IFN-I in primary human monocyte-derived macrophages [52]. Single stranded HIV-1 DNA engages the IFN-inducible protein 16 (IFI16) in the cytoplasm of macrophages, leading to the activation of the STING-TBK1-IRF3 pathway [52].

\section{Cellular Sources of IFN-I during HIV-1 Infection}

3.1. Plasmacytoid Dendritic Cells. Plasmacytoid DC are the most potent producers of IFN-I in response to viral infections $[16,53,54]$. Expression of endosomal TLR7 and TLR9 allows pDC to respond to both RNA and DNA viruses which are engulfed and trafficked into the endosomal pathway.
Upon TLR7/9 engagement, pDC can mature into antigenpresenting cells (APC) or IFN-I-producing cells (IPC), and the prevalence of one pathway over the other largely depends on the intracellular locale in which the TLR ligand triggers its receptor $[23,39]$. Thus, the engagement of TLR7/9 within the early endosomes causes strong activation of the IRF7 pathway via an IFN- $\alpha / \beta$-dependent positive feedback, resulting in the production of high quantities of IFN- $\alpha$ and $\mathrm{pDC}$ differentiation into IFN-I-producing cells (IPC) [39]. Conversely, if the TLR ligand is trafficked to the lysosomes or late endosomes, signal transduction via the NF- $\kappa \mathrm{B}$ pathway is favored, resulting in the upregulation of costimulatory molecules and maturation into APC [39]. O'Brien and colleagues reported that HIV-1 is preferentially trafficked to the early endosomes of $\mathrm{pDC}$, which in turn promotes a persistently activated IPC status, combined with partial or incomplete maturation [23].

The binding of the HIV-1 envelope glycoprotein gp120 to CD4, but not to the coreceptors CCR5 or CXCR4 is required for virion engulfment and subsequent activation of $\mathrm{pDC}$ via TLR7 engagement $[12,55]$. The interaction between gp120 and CD4 is stabilized by accessory interactions involving cellular adhesion molecules on both the cell membrane and viral envelope, allowing the formation of a stable binding interface between HIV-1 and the target cells [56-58]. Thus, the envelope of newly formed HIV-1 virions incorporates cellular proteins derived from the host cell of origin [56, 57, 59]; these cell-derived proteins contribute to virus-cell interactions and may modulate the dynamics of infection of target cells and uptake by endocytotic cells [57-60]. In addition, the HIV-1 envelope is not homogenous, but rather organized in a functional substructure enriched in tightly packed cholesterol, similar to the lipid rafts described in eukaryotic cells, including human leukocytes $[9,60,61]$. The organization of a functional virion-associated lipid raft is required to confer HIV-1 the ability to induce potent IFN-I production via $\mathrm{pDC}$ stimulation [9]. Thus, the efficiency of HIV-1 uptake by pDC and the potency of IFN-I induction are strongly reduced if envelope-associated cholesterol is withdrawn by chemical treatment [9]. However, cholesterol depleted HIV-1 partially retains the ability to promote pDC maturation into APC [9], suggesting that the integrity of the virion-associated lipid raft may not only reduce the efficiency of HIV-1 uptake, but also modify the dynamics of HIV-1 trafficking and subsequent TLR signalling in favour NF- $\kappa \mathrm{B}-$ mediated APC maturation rather than IRF7-dependent IFN$\alpha$ production.

Activation of pDC may occur within hours from exposure to HIV-1 in vivo. Intravaginal infection of rhesus macaques caused rapid accumulation of activated pDC at the mucosal site of infection, which resulted in macrophage inflammatory protein (MIP)- $3 \alpha$-mediated chemoattraction and infection of CCR5-expressing CD4 T cells, contributing to the spread of the infection to secondary lymphoid tissues [62]. Lubong Sabado and colleagues reported that $\mathrm{pDC}$ relocate to lymphoid tissues already during primary HIV-1 infection, a condition which persists throughout the course of disease [63]. However, reports on IFN- $\alpha$ secretion by $\mathrm{pDC}$ in lymphoid tissues during chronic HIV-1 infection showed contrasting results. For example, although IFN- $\alpha$ and upregulation of 
IFN-stimulated genes (ISG) has been reported in tissues from $\mathrm{HIV}+$ patients $[64,65]$, Nascimbeni and colleagues showed that $\mathrm{pDC}$ in the spleen of HIV-infected patients have an immature phenotype and do not contribute to the increased IFN- $\alpha$ production [66]. The state of partial or incomplete pDC maturation is confirmed in the study by Benlahrech and colleagues, who have recently shown that expression of the immunoglobulin-like transcript (ILT) 7, a regulatory receptor expressed by immature circulating pDC but not partially differentiated cells [36], is reduced in pDC from HIV-infected patients when viral replication is not efficiently controlled by therapy [67].

Recent evidence suggests that pDC may be the predominant source of IFN-I only during the initial phases of acute infection, whereas $\mathrm{mDC}$ and macrophages become important producers of IFN- $\alpha$ when the course of infection transitions to the early chronic phase [13]. Both $\mathrm{mDC}$ and monocyte/macrophages express TLR8, which has the potential to recognize viral RNA $[68,69]$. However, several studies have shown that in vitro maturation of $\mathrm{mDC}$ and monocyte in presence of HIV-1 is a bystander effect occurring in response to cytokines produced by HIV-1-activated pDC, such as IFN$\alpha$ and TNF- $\alpha[12,21-23]$. In addition, even in conditions in which TLR8 engagement occurs, $\mathrm{mDC}$ do not respond by secreting IFN-I, but rather mature into interleukin (IL)12 -secreting APC $[68,69]$. Thus, IFN-I production by $\mathrm{mDC}$ and macrophages during the post-acute and chronic phases of HIV-1 infection may depend on molecular pathways other than sensing of extracellular viral particles virus via endosomal TLR.

\subsection{Monocytes/Macrophages and Myeloid Dendritic Cells.} Endosomal TLR allow recognition of nucleic acids from viruses engulfed by specialized cells, but may not sense viral genomes which have gained access to the cytoplasm. Intracellular RLR and DNA sensors are triggered by viral genome in the cytoplasm and induce the production of antiviral and immunostimulatory cytokines, such as IFN- $\alpha$ and TNF- $\alpha$ [18]. RLR are expressed by most cell types and their triggering requires that the viral genome has reached the cytoplasm, a condition which is also necessary to achieve productive infection of the target cell. Conversely, TLR7/9mediated $\mathrm{pDC}$ responses would not be triggered during a productive infectious cycle, due to the segregation of the receptors in the endosomal compartment. This may represent a critical difference between IFN-I responses orchestrated by uninfected pDC during the early phases of viral exposure and IFN-I production by productively infected cells during later stages of infection.

This transition from a pDC-mediated to an apparently pDC-independent IFN-I response has been recently described in the HIV-1 simian model of simian immunodeficiency infection (SIV) of Rhesus macaques by Kader and colleagues [13]. Monocyte derived macrophages have been shown to respond to HIV-1 proviral DNA via intracellular DNA sensors [51, 52], and genomic HIV-1 RNA activates innate immune responses in peripheral mononuclear cells via RLR [41]. The question can be raised as to whether the main source of IFN-I changes during HIV-1 infection in relation to a shift in the distribution of productively infected cells among different cell types. Dendritic cells may act as catalysts for the infection of CD4 T cells via cell-cell transfer [70, 71], but activated CCR5+ CD4 $\mathrm{T}$ cells are the main target for infection and the main source of viral replication throughout the acute phase $[72,73]$. However, the number of CCR5+ T cells decreases progressively during acute infection both in the periphery and in lymphoid tissues, likely due to a combination of viral cytotoxicity, activation-induced apoptosis and immune-dependent killing mediated by newly activated HIV-1-specific cytotoxic CD8 T lymphocytes (CTL) [72-74]. Thus, as the pool of CCR5+ CD4 T cells decreases, CD4expressing $\mathrm{mDC}$ and monocyte/macrophages may become increasingly more important as targets for infection, and therefore more susceptible to activation via cytoplasmic RLR.

The critical questions that remain unanswered is whether the prolonged IFN-I response observed during pathogenic HIV-1/SIV infection plays a determinant role in viral immunopathogenesis and whether pDC-mediated acute responses or chronic IFN-I responses mediated by non-pDC subsets are potentially valuable targets for immunotherapeutic or curative interventions.

3.3. Other Cellular Sources of IFN-I. The broad expression of RLR and cytosolic DNA sensors in numerous cell types and in different tissues [18] suggests that any cell susceptible to HIV1 infection, and therefore to cytoplasmic exposure of viral RNA, has the potential to secrete IFN- $\alpha$ during HIV-1 infection. Nonetheless, evidence about IFN- $\alpha$ production by cells other than DC and monocytes is scattered and largely inconclusive about its relevance for systemic immune activation and immunopathogenesis. However, IFN- $\alpha$-producing cell subsets which are confided to specific anatomic locations may contribute to inflammatory processes within non lymphoid tissues and organs, partially accounting for the development of HIV-1-associated non-communicable comorbidities (NCCM). An increasing body of evidence suggests a causative link between chronic inflammation and some manifestations of NCCM. One example is that of neurological complications associated with neuroinflammation, which are observed even in patients in whom viral replication in controlled by combination antiretroviral therapy (cART) [75-77]. Thus, microglial activation and an IFN-driven gene regulation signature are characteristic of HIV-associated neurological symptoms, such as cognitive impairment and depressive disorder $[75,76,78,79]$. It is noteworthy that neurologic disease associated with infection with another human lymphotropic retrovirus, the human T-lymphotropic virus type 1 (HTLV1 ), is also associated with an IFN-dominated inflammatory profile. Thus, Tattermusch and colleagues described an IFN-inducible signature in HTLV-1-associated myelopathy/tropical spastic paraparesis (HAM/TSP) [80, 81]. It is still unclear whether peripheral sources of IFN-I, such as DC or macrophages are the sole responsible for the neuropathologic effects or whether astrocytes and microglial cells are directly involved in the production of IFN-I during the inflammatory response. Whether IFN-I production by these cells plays a role also in the immunopathogenesis of HIV-1 infection is yet to be determined. 


\section{Effect of IFN-I on Target Cells}

Type I IFN are the most potent natural mediators of antiviral activity in humans. The combination of proapoptotic and cytostatic activity, as well as the direct induction of intracellular viral restriction factors contribute to generate a cellular environment which is unsuitable for viral replication $[1,3,82$, 83]. The replication of HIV-1 is efficiently inhibited by IFNI in vitro, but the potential of IFN-I as antiretroviral agents during chronic HIV-1 infection in vivo is dubious [84-89].

IFN-I also contribute to the maturation of APC and exert a modulatory effect on different $\mathrm{T}$ cell subsets, therefore posing the foundations for promoting antigen-specific adaptive immune responses and shaping them according to the invading pathogen $[1,6,7,53,82,90]$.

4.1. IFN- $\alpha$ Receptor Complex and Signalling. The cellular effects of IFN-I are mediated by the engagement of a common receptor complex, the IFN- $\alpha$ receptor complex (IFNAR), which is expressed at different levels on the surface of virtually all human cells. The IFNAR complex is a heterodimer of the two subunits IFNAR1 and IFNAR2. Human IFNAR1 comprises an extracellular domain, a transmembrane region and an intracellular domain of 100 amino acid residues. Three different forms of IFNAR2 have been described: the full length receptor chain which includes a 250 residues cytoplasmic portion, an alternative form with a shorted intracellular portion (67 residues) [91, 92] and a soluble form lacking the transmembrane and cytoplasmic portions [91]. Human IFNAR2 binds all human IFN-I with higher affinity than IFNAR1, but the affinity of the IFNAR heterodimer for most human IFN-I is 10 fold higher than IFNAR2 alone [91, 93, 94].

The cytoplasmic domains of IFNAR1 and IFNAR2 are associated with the tyrosine kinase (TYK)-2 and janus kinase (JAK)-1, respectively [91]. Upon IFN-I binding to the IFNAR complex, the tyrosine kinases are activated and orchestrate the signal transduction machinery [95]. TYK-2 and JAK-1 phosphorylate tyrosine residues on the IFNAR, and phosphorylated tyrosines act as docking sites for the src-homology-2 (SH2) domains of signal transducer and activator of transcription (STAT) proteins, which are then targeted for phosphorylation $[96,97]$. STAT1, STAT2, STAT3, and STAT5 are expressed and activated by IFN-I in most cell types, whereas IFN-I-induced activation of STAT4 and STAT6 is limited to lymphocytes [96, 97].

STAT2 is recruited to the IFNAR1 cytoplasmic domain and is phosphorylated by TYK-2, serving as a lure for STAT1 [98], which is also phosphorylated at tyrosine 701. The STAT1STAT2 heterodimer associates with the DNA binding protein interferon regulatory factor 9 (IRF9) to form a signalling complex called IFN-stimulated gene factor-3 (ISGF3). The ISGF3 complex translocates to the nucleus where it promotes the transcription of IFN-I-stimulated genes (ISG) by interacting with the IFN-stimulated response elements (ISRE), usually situated within 200 base pairs of the transcription start site. An additional phosphorilation of STAT1 at serine 727 , mediated by protein kinase C- $\delta$ (PKC- $\delta$ ), is essential for efficient transcriptional activity $[1,98]$. In addition, STAT1 homodimers can bind to IFN- $\gamma$-activated site (GAS) in the promoter region of IFN-I-stimulated genes $[99,100]$. Thus, while IFN-I can activate genes containing either ISRE or GAS promoter elements, IFN- $\gamma$ is unable to induce the formation of ISGF3 and activate genes via ISRE [101]. Signalling via STAT1-STAT2 is responsible for some of the most commonly observed effects of IFN-I during chronic HIV-1 infection, including the activation of proapoptotic and cytostatic genes, viral restriction factors and immunomodulatory effects [102104].

Type I IFN also triggers phosphorylation of STAT3 [105], promoting its dimerization and migration to the nucleus. STAT3 homodimers activate the transcription of genes containing the enhancer sequence STAT3-binding element (SBE). Despite sharing high sequence similarity with STAT1, STAT3 activation induces a gene expression profile distinct from that dependent on STAT1-STAT2 [106], including genes of the B cell lymphoma (BCL) family and the oncogene MYC, which promote proliferation and antagonize apoptosis $[107,108]$. Furthermore, STAT3 is responsible for the suppression of inflammatory responses via IL-10, which directly counteracts STAT1 activity [109].

IFN- $\beta$ also activates the signal transduction pathway mediated by JAK1 and phosphoinositide 3-kinase (PI3K), leading to the expression of genes regulated by cyclic adenosine monophosphate (cAMP) via the nuclear translocation of cAMP-responsive-element (CRE) binding protein (CREB). Similar to the STAT3-mediated pathway, PI3K signalling can also result in IL-10 production by DC [110]. However, the two pahways appear to be independent from each other. The mammalian target of rapamycin (mTOR) is activated downstream of the PI3K signalling cascade [111]. Activation of mTOR is independent of STAT signalling and does not modify the gene expression profile, but modulates mRNA translation by regulating the activation of p70 S6 kinase and the phosphorylation of the ribosomal protein S6 [112, 113].

The signalling pathway mediated by p38 mitogen-activated protein kinases (p38-MAPK) and extracellular signalregulated kinase (ERK) 1 or ERK2 is also activated by IFN-I. Thus, genes which contain ISRE and GAS elements in their promoter region can be upregulated via a STAT-independent pathway mediated by p38-MAPK [114-116], and the cytostatic and antiviral effects of IFN-I are dependent on intact p38MAPK signalling machinery [117-120].

It is reasonable to expect that different IFN-I signal transduction pathways are activated during HIV-1 infection. However, the STAT1-STAT2 pathway is arguably the best described in the setting of IFN-I production during HIV1 infection. The activation of STAT proteins by HIV-1 was described in different experimental conditions involving HIV-1-induced IFN-I production, productive HIV-1 infection of target cells or simple exposure to viral proteins. Thus, in vitro exposure of cell lines or primary leukocytes to whole HIV-1 virions was repeatedly shown to activate STATdependent pathways in CD4 T cells and cells of the monocytic lineage [55, 121, 122]. Interestingly, Renga and colleagues reported that exposure of monocytic cell lines to the HIV-1 matrix protein p17 was sufficient to activate the JAK1/STAT1 axis and cause upregulation of STAT1 sensitive genes [123], suggesting that STAT1 activation during HIV-1 infection may 
also occur independent of IFN-I production. Simian immunodeficiency virus (SIV) infection of nonhuman primates in vivo resulted in upregulation of gene expression for STAT1, STAT2 and IRF9 during the acute phase of infection, which was protracted through the early chronic phase only in disease susceptible primate species, not in disease resistant African species $[124,125]$. Although signalling via the ISGF3 complex is regulated by post-transcriptional modification of STAT proteins, not by modulation of STAT and IRF9 gene expression, the observed increases in the expression of these molecules in SIV-infected macaques $[124,125]$ is indicative of enhanced activity of the IFN-I/ISGF3 axis.

The central role played by PI3K in multiple signal transduction pathways renders it difficult to distinguish its participation in mediating the effects of IFN-I from other biochemical, cellular and molecular events occurring during HIV-1 infection. The contribution of PI3K in neuroinflammation associated with HIV-1 infection has been described [126-128], but the role of $\mathrm{Pi} 3 \mathrm{~K} / \mathrm{mTOR}$ in HIV-1 immunopathogenesis remains unclear.

Activation of the p38-MAPK pathway during HIV-1 infection has been described by several groups [129-139]. However, studies on the p38-MAPK/ERK pathway have generally focused on the direct effect of HIV-1 gp120 singalling via engagement of CD4 or the coreceptors CCR5 and CXCR4 [129, 136-139], rather than IFN-I production. In particular, activation of $\mathrm{p} 38$-MAPK/ERK has been studied in reference to its role in modulating cell activation and HIV-1 replication [129-135].

4.2. Expression Pattern of IFNAR. Type I IFN are generally considered to exert their biologic effect on virtually all human cells. This broad and noncell specific activity reflects the prominent innate antiviral function of IFN-I, which needs to reach any potential target of viral infection.

However, cell-specific differences in the responsiveness to IFN-I signalling have been observed in humans, particularly among immune effector cells. Thus, IFN-I inducing TLR9 agonists, as well as HIV-1, efficiently upregulated the expression of the IFN-I regulated gene PDL1 on primary human monocytes and a subset of T lymphocytes, identified by selective expression of the chemokine receptor CCR5 [21]. Analysis of IFNAR2 expression in T lymphocytes revealed that this subunit of IFNAR was almost exclusively restricted to CCR5+ T cell subsets, independent of whether CD4 or CD8 $\mathrm{T}$ cells were considered [21]. A similar restriction of IFN-I signalling to CCR5+ T cells was observed when HIV1-induced upregulation of the T cell activation markers CD38 and CD69 was analyzed in vitro $[9,140]$.

In both humans and non-human primates, CCR5 expression is generally higher in memory and effector $\mathrm{T}$ cell subsets [141-144], and natural disease-resistant SIV host species, such as sooty mangabeys, show reduced levels of CCR5+ CD4 $\mathrm{T}$ cells compared to disease susceptible hosts such as humans and Rhesus macaques $[142,143]$. The role played by CCR5 as coreceptor for HIV-1 and SIV Env proteins, providing the critical mechanism for envelope-membrane fusion and injection of the viral RNA into the cytoplasm, provided the basis for investigating how differences in CCR5 expression between different species translate into different transmission and disease progression phenotype [142, 145]. However, little attention has been given to the possibility that different profiles of CCR5 expression among primate species may account for different sensitivity to IFN-I production, and therefore different patterns of regulation of IFN-I-stimulated genes during chronic HIV-1 or SIV infection, ultimately accounting for differences in disease susceptibility.

4.3. Cytostatic and Proapoptotic Effects. Type I IFN are widely recognized as the most potent natural mediators of antiviral activity in humans $[1,3]$. Because the life cycle of viruses is directly influenced by the intracellular environment, efficient antiviral mechanisms have developed to interfere with basic cellular functions or, in an even more resolute manner, eliminate infected cells which represent the factories of viral replication. These goals are achieved by IFN-I via the upregulation of genes exerting cytostatic and proapoptotic activities. The broadly effective antiviral mechanisms include the induction of molecular mechanisms interfering with protein synthesis and cellular activity, as well as the stimulation of ligand/receptor-dependent apoptotic pathways and stress responses. While exerting potent antiretroviral activity, these mechanisms clearly interfere with basic cellular functions and carry a potentially destructive risk for the host, hence the need for tight regulation of both the kinetic of activation and the restriction to specific anatomical locations.

During HIV-1 infection, the chronic induction of IFN-I responses may contribute to progressive immunodeficiency $[10,146]$.

4.3.1. Ligand-Receptor Mediated Apoptosis. Type I IFN positively regulates the expression of tumor necrosis factor (TNF) family members, capable of inducing apoptosis in cells which express specific receptors. Thus, expression of FAS ligand (FasL), TNF-related apoptosis inducing ligand (TRAIL) and programmed death ligand $(\mathrm{PDL}) 1$, are all directly regulated by IFN-I signalling [21, 146-148].

The contribution of the Fas/FasL system to CD4 T cell apoptosis during HIV-1 infection is well documented [149151], and similar findings were reported for IFN-I-induced TRAIL and its death receptor (DR) 5 [55, 65, 121, 152, 153]. TRAIL expression following HIV-1 exposure or infection has been described in T cells, monocytes, and pDC [24, 55, 153, 154], and TRAIL expressing pDC have been shown to directly induce apoptosis of CD4 T cells in HIV-1 infected patients with high viraemia [153]. TRAIL mediated apoptosis in the setting of HIV-1 stimulation in vitro was originally reported to affect CD4 T cells, but not CD8 T cells $[55,65,152]$. Interestingly, TRAIL mediated CD4 T cell apoptosis did not require productive infection, and TRAIL expressing $\mathrm{pDC}$ were reported to be unable to lyse HIV-1 infected CD4 T cells [155] possibly favouring the depletion of uninfected CD4 T helper cells in the face of CD4 T cell viral reservoirs preservation. However, Zhu et al. later described TRAIL dependent apoptosis in HIV-1 infected macrophages, as a result of the downregulation of a decoy receptor [156]. Thus, TRIAL induced apoptosis may contribute to regulating 
the balance between clearance of HIV-1 infected cells and depletion of CD4 T helper cells.

Upregulation of PDL1 on circulating monocytes and T cells during HIV-1 infection was originally described to correlate with active viral replication [157]. The report of a causative link between IFN-I secretion and PDL1 expression after exposure to HIV-1 also indicated that CCR5 expression on $\mathrm{T}$ cells is associated with sensitivity to IFN-I signalling, determined by increased expression of IFNAR2 [21]. PDL1 engages its receptor $\mathrm{PD} 1$ on T lymphocytes to suppress proliferation and induce apoptosis [158]. During HIV-1 infection, PD1 is highly expressed by exhausted dysfunctional HIV-1specific T cells [159], and blockade of PD1-PDL1 interaction enhances HIV-1-specific T cell immunity and immune-mediated control of viraemia in humanized mice and simian models of HIV-1 infection [160-164]. Thus, upregulation of PDL1 via IFN-I may directly contribute to the impairment of efficient antiviral $\mathrm{T}$ cell responses and to the perpetuation of HIV-1 infection.

4.3.2. P53-Mediated Apoptosis. The existence of a functional connection between IFN $-\alpha / \beta$ and $\mathrm{p} 53$ we formally reported by Takaoka and coworkers in 2003 [165]. The relevance for IFN-I-induced p53 activation for viral infections was highlighted by Vilček, who postulated that IFN-I-mediated activation of the STAT1-STAT2-IRF-9 complex (ISGF-3) during viral infection may promote $\mathrm{p} 53$ gene expression via two ISRE sites in the $\mathrm{p} 53$ gene promoter [83].

Doitsh and colleagues reported that the accumulation of reverse transcription intermediates in CD4 T cells undergoing abortive HIV-1 infection results in apoptotic death [166]. The apoptotic pathway induced by abortive infection was associated with the production of inflammatory cytokines, including IL- $1 \beta$ and IFN- $\beta$, and involved activation of caspase- 1 and caspase-3 [166]. However, the authors found no evidence of p53 involvement [166].

4.4. Viral Restriction Factors. HIV-1 infection and replication within infected cells can be inhibited at different steps of the viral life cycle by restriction factors regulated by IFN-I.

4.4.1. Interferon Stimulated Gene 15 (ISG15). The $15 \mathrm{kDa}$ product of the IFN-stimulated gene (ISG) 15 was originally identified as a ubiquitin homologue ${ }^{13}$. Similar to ubiquitin, ISG15 acts as a tag for cellular proteins via covalent binding mediated by specific enzymes, which are also positively regulated by IFN-I [167-170]. However, different from ubiquitin, the primary effect of tagging with ISG15 (often referred to as ISGylation) does not appear to be proteasomal degradation. For example, ISGylation favours the sustained production of IFN- $\beta$ in virus-infected cells by preventing the degradation of IRF3 [171] and enhances NF- $\kappa$ B signalling by inhibiting the activity of the protein phosphatase 1B (PPM1B) [172].

ISG15 has been shown to exert broad antiviral activity in both mice and humans [167]. The anti-HIV-1 activity of ISG15 is mediated via inhibition of the ubiquitylation of the capside protein Gag and of the cellular protein encoded by the tumor susceptibility gene (Tsg)101 [173, 174]. Ubiquitylation of Gag and Tsg101 is required for the release of virions from infected cells, a process which is therefore inhibited by ISGylation [173, 174].

4.4.2. Myxovirus Resistance (Mx) GTPases. Type I IFN induce the expression of proteins involved in membrane rearrangement leading to vesicle budding, organogenesis and cytokinesis. Some of these proteins may contribute to host resistance to pathogens, including the p47 and p65 guanylatebinding proteins (GBP), inducible GTPases and the myxovirus resistance $(\mathrm{Mx})$ proteins [175]. In particular, the $\mathrm{Mx}$ proteins have been widely studied for their antiviral activity and their expression is strictly regulated by IFN-I [176].

Two Mx proteins have been identified in humans, MxA and $\mathrm{MxB}$. MxA exerts inhibitory effect on a wide range of viruses [167]. $\mathrm{MxB}$ was recently described as a novel restriction factor for HIV-1 [177, 178]. The mechanism of HIV1 inhibition is not fully elucidated, but the viral cycle is blocked after viral entry and before proviral DNA integration $[177,178]$. In addition, binding to the capsid protein gag is required for the antiviral activity $[177,178]$.

4.4.3. $2^{\prime}-5^{\prime}$-Oligoadenylate Synthetase (OAS) and RNaseL Pathway. The $2^{\prime}-5^{\prime}$-oligoadenylate synthetase (OAS) proteins are IFN-I inducible enzymes which polymerize ATP into oligomers of adenosine generated with noncanonical $2^{\prime}-5^{\prime}$ bonds $[179,180]$. These $2^{\prime}-5^{\prime}$ adenosine oligomers induce activation of RNaseL, which mediates degradation of RNA from invading viruses and suppression of cellular activities [181]. Degraded RNA may also activate cytoplasmic RLR, resulting in IFN-I production and amplification of the antiviral innate responses [182].

Specific anti-HIV-1 activity by the OAS-RNaseL axis has been described in transfected cell lines [183]. Although the in vivo relevance of this antiviral system for HIV-1 inhibition is still to be determined, it is reasonable to speculate that the non virus specific effect of RNaseL may partially affect HIV-1 activity in target cells.

4.4.4. Protein Kinase RNA-Activated (PKR). The protein kinase RNA-activated (PKR) is involved, together with other members of the same family of protein kinases, in the response to environmental stress. Kinases in this family regulate the rate of protein synthesis by phosphorylating the $\alpha$-subunit of the eukaryotic initiation factor (EIF) 2 , which result in the sequestration of guanine-nucleotide exchange factor EIF $2 \beta$, ultimately preventing the recycle of guanidin diphosphate (GDP) which is strictly necessary for protein synthesis [184].

PKR is constitutively expressed in all cell types in an inactive monomeric form and converts active homodimers following autophosphorylation at key residues [185-188]. The presence of two RNA-binding motifs in the N-terminal region allows for direct activation of PKR by RNA $[189,190]$.

$\mathrm{PKR}$ is a potent inhibitor of HIV-1 replication in human cell lines in vitro, but exerts lower inhibitory activity in primary cells [191-196], questioning the in vivo relevance of PKR-mediated anti-HIV-1 activity. HIV-1 messenger RNA contain a target sequence at the $5^{\prime}$ end which is recognized by 
the transactivating accessory protein Tat; the trans-activating response (TAR) RNA element plays a critical role in activating transcription [197-199]. PKR is sensitive to changes in the cytoplasmic concentration of TAR RNA sequences, in that low amounts of TAR induce PKR activation, whereas high TAR RNA concentrations exert an inhibitory effect on PKR activity [200-202].

4.4.5. Tripartite Motif (TRIM) Proteins. Members of the tripartite motif (TRIM) protein family participate in a broad range of cellular functions, including apoptosis and antiviral immunity [203]. Several TRIM proteins have been described for their ability to restrict retroviruses replication and many are directly regulated by IFN-I in humans, including TRIM5 and TRIM22 [204-208].

TRIM5 is one of the best studied members of the TRIM family, mainly because of its inhibitory activity against HIV-1. TRIM5 blocks HIV-1 infection in the cytoplasm, before reverse transcription is completed, by recognizing and binding the capsid protein lattice, thus interfering with the uncoating and ultimately with reverse transcription [209]. The antiretroviral effect is strictly dependent on TRIM5 E3 ubiquitin ligase activity $[210,211]$, and is associated with proteasome recruitment $[212,213]$. TRIM5 itself is ubiquitinated and degraded when it exert inhibitory activity on restriction-sensitive viruses [210, 211, 214, 215]. However, it is still unclear whether ubiquitination of HIV-1 capsid occurs. TRIM5 proteins from different nonhuman primate species show varying potency of anti-HIV-1 activity. The macaque and owl monkey TRIM5 orthologues have been particularly well studied, due to the potent inhibition of HIV-1 infection in cells from these species [216, 217], which is associated with strong interaction with the HIV-1 virion core [218]. The human TRIM5 orthologue shows relatively low inhibitory activity on lab-adapted HIV-1 stains [205, 219], but it is 10fold more potent on certain primary HIV-1 isolates [220].

TRIM5 contributes to control viral transmission and replication in SIV-infected non human primates [221-225], and differences in the rate of disease progression in HIV1 infected patients correlate with TRIM5 expression and polymorphisms [226-229]. In addition, Battivelli and colleagues reported that HIV-1 variants selected by cytotoxic $\mathrm{T}$ lymphocyte pressure to escape $\mathrm{T}$ cell recognition may be highly sensitive to restriction by human TRIM5 [230].

In addition to its well-studied antiviral activity, TRIM5 has been the subject of studies characterizing its role as a pattern recognition receptor (PRR) for the protein lattice of retroviral capsid. TRIM5 is required for dendritic cell activation in response to lipopolysaccharide (LPS) [211], and the signal transduction pathways involving AP- 1 and NF- $\kappa \mathrm{B}$ are activated by TRIM5 [211, 231]. Thus, the interaction of TRIM5 with the HIV-1 capsid lattice enhances the induction of inflammatory cytokines [211].

Other TRIM proteins have been studied for their ability to interfere with HIV-1 replication. Human TRIM22 efficiently inhibits HIV-1 transcription and replication in primary human monocyte derived macrophages [232, 233]. TRIM22 exert its antiviral activity after HIV-1 integration, and E3 ubiquitin ligase activity is not necessary for
TRIM22-mediated inhibition of HIV-1 replication [234]. Depending on the cell type and subcellular localization, TRIM22 can inhibit HIV-1 transcription at nuclear level [234] or virion production in the cytoplasm [204].

4.4.6. Apolipoprotein B-Editing Catalytic Polypeptide 3 (APOBEC3) Proteins. The anti-HIV-1 activity of proteins of the apolipoprotein B-editing catalytic polypeptide 3 (APOBEC3) family was originally described in an effort to characterize the function of the HIV-1 accessory protein virion infectivity factor (Vif), which is required for HIV-1 replication in primary $\mathrm{CD} 4^{+} \mathrm{T}$ cells and certain cell lines, but not in fully permissive lines. Further studied demonstrated that the human gene APOBEC3G is a potent inhibitor of the replication of Vif-deficient HIV-1 [235].

The inhibition of HIV-1 replication by APOBEC3G (A3G) relies on its cytidine deaminase activity on both RNA and DNA, causing the conversion of cytidine residues into uridines [236-238]. This process results in both the alteration of the nucleotide sequence and the insertion of nonnatural bases (uredines) into the DNA strand [236-238]. The enzymatic activity of $\mathrm{A} 3 \mathrm{G}$ is selective for the third cytidine in $5^{\prime}$ CCCA-3' sequences $[237,238]$. As a consequence of cytidineto-uridine mutation, the levels of HIV-1 cDNA in infected cells are diminished. It was initially thought that uredinecontaining DNA was degraded by host DNA repair enzymes, but inhibition of uracil DNA glycosidases is ineffective in restoring HIV-1 cDNA levels [239]. It has been suggested that A3G activity may interfere with the progression of the reverse transcriptase along the viral RNA template [240, 241].

One important characteristic of $A 3 G$ is the fact that, unless counteracted by Vif, it is packaged into assembling HIV-1 virions [242]. Thus, A3G-bearing virions can transfer the restriction factor to target cells [237, 243-245].

The viral accessory protein Vif potently inhibits the antiviral activity of $\mathrm{A} 3 \mathrm{G}$ by recruiting it for polyubiquitination and proteasomal degradation, thus preventing $\mathrm{A} 3 \mathrm{G}$ incorporation into newly formed virions [244, 246-248].

Other human APOBEC proteins have been shown to exert anti-HIV-1 activity in vitro. However, only APOBEC3F (A3F) and APOBEC3H (A3H) haplotype II appear to have a significant effect in vivo [249], even though they appear to have lower potency and lower expression than A3G. Accordingly, A3G, A3F, and A3H are the only APOBEC3 proteins counteracted by Vif, suggesting a dynamic evolutionary interplay between host restriction factors and viral escape mechanisms.

4.4.7. Bone Marrow Stromal Cell Antigen 2 (BST2, Tetherin). The bone marrow stromal cell antigen 2 (BST2 or tetherin) is transmembrane protein with glycophosphatidylinositol lipid anchor at the C-terminal domain, an extracellular $\alpha$-helix domain and a N-terminal transmembrane anchor [250]. Similar to A3G, tetherin was described as the IFN-I-induced cellular restriction factor inhibited by a HIV-1 accessory protein, namely $\mathrm{Vpu}[85,86,251,252]$. Thus, in the absence of $\mathrm{Vpu}, \mathrm{HIV}-1$ virions budding from productively infected cells are trapped or tethered (hence the name tetherin) on 
the surface of infected cells $[85,86,251,252]$. Tethered virions are eventually internalization and accumulate in endosomes [251].

Tetherin exert antiviral activity on several families of viruses [253-255], and it preserves antiviral activity in the face of extensive mutations [256], suggesting that its function is not strictly dependent on recognition of specific viral protein sequences.

HIV-1 evades the antiviral effect of tetherin thanks to the accessory protein Vpu $[86,252]$. Vpu directly binds tetherin, and causes a general decrease in tetherin expression on the cell surface [252]. Different mechanisms have been suggested to account for Vpu-mediated counteracting of tetherin activity, including alterations of trafficking pathways [257, 258], and enhanced proteasomal degradation [259-261].

Other human and nonhuman primate lentiviruses have developed mechanisms of evasion for tetherin-mediated antiviral activity. Thus, most SIV do not encode Vpu, and tetherin is antagonized by the Nef protein $[262,263]$. Conversely, the Env protein of HIV-2, which also does not encode $\mathrm{Vpu}$, has evolved to interfere with tetherin and cause it to be sequestered within intracellular compartments $[264,265]$.

4.4.8. Sterile $\alpha$ Motif (SAM) and Histidine-Aspartic (HD) Domain-Containing Protein 1 (SMAHD1). Studies on the function of another lentiviral accessory protein, the viral protein $\mathrm{x}(\mathrm{Vpx})$, brought to the discovery of the restriction factor sterile $\alpha$ motif (SAM) and histidine-aspartic (HD) domaincontaining protein 1 (SMAHD1).

Vpx is expressed by HIV-2 and related viruses (such as SIVsm) but not by HIV-1 [266]. HIV-1 infection of human monocyte-derived dendritic cells is enhanced in presence of exogenous Vpx or if HIV-1 is genetically modified to encode for Vpx [267, 268], and HIV-2 reverse transcription in monocyte-derived macrophages is strictly dependent on $\mathrm{Vpx}$ [269]. A number of studies contributed to identify SAMHD1 as the target of Vpx-driven ubiquitylation and subsequent proteosomal degradation. Thus, SAMHD1 ubiquitylation is mediated by the cullin-4A ubiquitin ligase (CUL4A)-DNA damage-binding protein 1 (DDB1) complex (CUL4A-DDB1), which is assembled by Vpx via recruitment of the DDB1 CUL4A associated factor 1 (DCAF1) [270-273].

SAMHD1 exerts phosphohydrolase activity, and can degrade deoxyribonucleotides triphosphate (dNTP) to deoxynucleoside and inorganic triphosphate [274]. Reverse transcription relies on the availability of $\mathrm{dNTP}$, and the anti-HIV1 effect of SAMHD1 is mediated via its dNTPase activity, which causes a reduction of the pool of intracellular dNTP to a level incompatible with viral replication [275]. SAMHD1 is exclusively localized in the nucleus [276-278], whereas reverse transcription occurs in large part in the cytoplasm, suggesting that dNTP hydrolysis in the nucleus has deleterious repercussions on the cytoplasmic availability of dNTP.

SAMHD1 is expressed at constitutively high levels by cells which are nonpermissive with regards to HIV-1 infection, such as monocytes and monocyte-derived DC [271]. However, HEK293T cells, undifferentiated THP-1 cells and activated $\mathrm{CD} 4^{+} \mathrm{T}$ cells are not refractory to HIV-1 infection despite expressing SAMHD1 [270, 275], suggesting that the antiviral activity of SAMHD1 may be biologically important only in differentiated or non-dividing cells such as DC and macrophages. The high rate of dNTP turnover in dividing cells, overcoming the dNTPase activity, may in part explain the susceptibility to lentiviral infection despite SAMHD1 expression. SAMHD1 can be upregulated in human monocytes and monocyte-derived DC by either type I or type II IFN $[279,280]$.

4.5. Immunostimulatory and Modulatory Activites. Type I IFN play a pivotal role in the transition from innate to adaptive immune responses by both stimulating maturation of APC and by directly modulating and shaping $\mathrm{T}$ cell function.

4.5.1. Effect of IFN-I on APC Differentiation and Maturation. IFN-I stimulates monocytes differentiation into DC in vitro [281-284]. However, the presence of IL-4 in the in vitro culture of monocyte appears to modify the effects of IFN-I, likely due to the ability of IL-4 to attenuate the expression of ISG [285]. Thus, the ultimate effect of IFN-I stimulation on the differentiation of monocytes into DC may depend on the cytokine milieu in the surrounding environment and the timing of exposure to different stimuli.

Importantly, IFN-I promotes the maturation of DC to fully competent APC by inducing upregulation of the costimulatory molecules CD40, CD80, and CD86 and by enhancing the expression of MHC class I and II [6, 7, 286, 287]. These changes in DC phenotype correspond to increased ability of IFN-I-stimulated DC to stimulate $\mathrm{T}$ cell proliferation in vitro $[6,7,286,287]$.

Following IFN-I stimulation, DC secrete IL-15, which exert stimulatory effects on $\mathrm{T}$ cells and promotes DC maturation $[282,288]$. In addition, IL-10 and the TNF family members B lymphocyte stimulator protein (BlyS) and APRIL are also expressed by DC following IFN-I stimulation [289-291]. When expressed in combination with IL-10 or transforming growth factor (TGF) $\beta$, APRIL can induce T cell independent immunoglobulin class switching [291]. IL-10 is a potent antiinflammatory mediator, its production in response to IFNI highlights the dichotomous role that IFN-I may play in balancing immune activation and immune suppression [289]. Accordingly, the effect of IFN- $\alpha / \beta$ on IL- 12 production can be either stimulatory or inhibitory [292-294]. The maturation stage of DC and the dose of IFN-I to which they are exposed may all affect IL-12 production, as well as the interaction of IFN-I with other stimuli $[295,296]$. Changes in the secretion of IL-12 may then affect the quality of the DC-activated T cell response by modulating the induction of IFN- $\gamma$-secreting cells as well as the production of other cytokines, such as IL-4, IL-5, IL-10, and IL-13 [289].

The secretion of chemokine is also modulated by IFN-I. Monocyte-derived immature DC secrete the CXCR3-binding chemokines CXCL9, CXCL11, and CXCL10 in response to IFN-I stimulation [287]. CXCR3 is expressed by activated T and B cells [297], which may be recruited to sites of inflammation. In addition, IFN-I induces DC-mediated secretion of CXCL19 (MIP-3 $\beta$ ), which recruits naive T cells and may therefore contribute to initiating adaptive $\mathrm{T}$ cell responses [298]. 
4.5.2. Modulation of T Cell Response. The direct effect of IFNI on proapoptotic and immunoregulatory ligands, such as FasL, TRAIL, and PDL1, has been discussed in Section 4.3.

The influence that IFN-I exert on APC maturation and cytokine production underscore the key role played in the differentiation of both CD4 and CD8 T cells. Thus, the enhancement of IL-12 production observed when DC are matured in presence of IFN-I, induces STAT4 activation and subsequent T-bet expression in CD4 T cells, which drive the differentiation into IFN- $\gamma$-producing $\mathrm{T}$ helper (Th)1 cells [299]. In addition, IFN-I directly act on human T cells to induce STAT4 activation [300, 301], which is however not sufficient on its own to drive Thl commitment in vitro [302, 303]. Conversely, in presence of other cytokines, such as IL-18 and IL-21, IFN-I efficiently promotes Th1 cell differentiation and effector functions [304-306].

In parallel to the positive effects on Thl differentiation, IFN-I may inhibit or reverse CD4 T cell differentiation into other Th types. Thus, Th2 responses are negatively regulated by IFN-I in human cells via the suppression of the Th2-driving transcription GATA-binding protein 3 (GATA3) [304]. Furthermore, suppression of Th17 differentiation by IFN-I has been described in both murine and human cells $[307,308]$.

IFN-I may also contribute to negatively modulate $\mathrm{T}$ cell response by regulating the function of $\mathrm{CD} 4$ regulatory $\mathrm{T}$ cells (Treg), which play a critical role in the maintenance of immunological tolerance and homeostasis. Studies conducted in patients with relapsing-remitting multiple sclerosis have highlighted how administration of IFN- $\beta$ treatment enhanced both the frequency and suppressive function of $T_{\text {Reg }}$ cells [130].

The primary response of CD8 T cell against viral infection, epitomized by proliferation and clonal expansion, can be enhanced in presence of IFN-I, which is also critical in allowing the generation of memory CD8 T cells [309-311]. However, secondary CD8 and CD4 T cell responses against viral antigens, including HIV-1, may be inhibited in presence of high levels of IFN-I $[9,21]$. Thus, the effect of IFN-I on T cell responses may largely depend on the stimulation condition and the cell types affected, in that IFN-I may favour costimulatory signals during primary antigenspecific responses by naive $\mathrm{T}$ cells, but suppress secondary memory responses against recall antigens via the induction of cytostatic and proapoptotic mechanisms.

\section{Conclusion and New Perspectives}

Type I IFN play a central role in the coordination of a multitude of immune effector and regulatory mechanisms. The ultimate effect of IFN-I on the overall economy of an effective antiviral immune response may depend on the mechanism of induction, the cellular source, and the timing of production.

Plasmacytoid DC may respond rapidly to viral exposure. The ability of pDC to secrete IFN-I in response TLR7/9 signalling indicates that these cells do not require the viral genome to enter the cytoplasm, meaning that they produce IFN-I independent of whether they are productively infected
(Section 2.1). Combining IFN-I production with the potential to mature into APC, pDC may be the ideal candidate to promote efficient antiviral primary $\mathrm{T}$ cell responses, by favouring CD4 T cell differentiation into Th1 cells and favouring the activation and clonal expansion of virus-specific naive CD8 $\mathrm{T}$ cells (Sections 3.1 and 4.5).The local production of IFN-I at the site of infection by pDC also favours the induction of antiviral mechanisms which may limit the spread of infection (Section 4.4).

When productive infection of some tissue target cells is established, IFN-I production may be sustained by infected cells which do not normally exert immune function, but can react to viral genomes in the cytoplasm via specific sensors (Sections 2.2 and 2.3). Although limited in terms of amount of IFN-I produced on a per cell basis, this second pDCindependent wave of IFN-I production may be more focused and circumscribed to the foci of potential viral replication, and efficiently inhibit virus spread to other cells without interfering with adaptive immune responses.

During HIV-1 infection, both the early pDC-mediated and the late pDC-independent IFN-I responses may be dysfunctional and cause severe damage to the development and maintenance of adaptive anti-HIV-1 responses. Thus, the organization of the HIV-1 envelope into a functional lipid raft may favour an overwhelming induction of pDC-mediated persistent IFN-I responses over antigen-presenting function (Section 3.1), which may prevent the efficient promotion of primary CD4 Th1 and CD8 T cell responses. Subsequently, the tropism of HIV-1 for immune cells, including DC and monocyte/macrophages, may result in the prolonged production of IFN-I in lymphoid tissues by HIV-1-infected professional APC, which may compromise the induction of secondary HIV-1-specific responses and contribute to the perpetuation of infection and disease progression.

\section{References}

[1] J. Bekisz, H. Schmeisser, J. Hernandez, N. D. Goldman, and K. C. Zoon, "Human interferons alpha, beta and omega," Growth Factors, vol. 22, no. 4, pp. 243-251, 2004.

[2] S. J. Neil, "The antiviral activities of tetherin," Current Topics in Microbiology and Immunology, vol. 371, pp. 67-104, 2013.

[3] C. E. Samuel, "Antiviral actions of interferons," Clinical Microbiology Reviews, vol. 14, no. 4, pp. 778-809, 2001.

[4] C. Scagnolari and G. Antonelli, "Antiviral activity of the interferon alpha family: biological and pharmacological aspects of the treatment of chronic hepatitis c," Expert Opinion on Biological Therapy, vol. 13, pp. 693-711, 2013.

[5] U. Kalinke and M. Prinz, "Endogenous, or therapeutically induced, type I interferon responses differentially modulate Th1/Th17-mediated autoimmunity in the CNS," Immunology and Cell Biology, vol. 90, pp. 505-509, 2012.

[6] D. F. Tough, "Modulation of t-cell function by type i interferon," Immunology \& Cell Biology, vol. 90, pp. 492-497, 2012.

[7] J. M. González-Navajas, J. Lee, M. David, and E. Raz, "Immunomodulatory functions of type i interferons," Nature Reviews Immunology, vol. 12, no. 2, pp. 125-135, 2012.

[8] L. Frasca and R. Lande, "Overlapping, additive and counterregulatory effects of type II and i interferons on myeloid dendritic 
cell functions," The Scientific World Journal, vol. 11, pp. 20712090, 2011.

[9] A. Boasso, C. M. Royle, S. Doumazos et al., "Overactivation of plasmacytoid dendritic cells inhibits antiviral T-cell responses: a model for HIV immunopathogenesis," Blood, vol. 118, no. 19, pp. 5152-5162, 2011.

[10] A. Boasso and G. M. Shearer, "Chronic innate immune activation as a cause of HIV-1 immunopathogenesis," Clinical Immunology, vol. 126, no. 3, pp. 235-242, 2008.

[11] A. Benlahrech and S. Patterson, "HIV-1 infection and induction of interferon alpha in plasmacytoid dendritic cells," Current Opinion in HIV and AIDS, vol. 6, no. 5, pp. 373-378, 2011.

[12] A.-S. Beignon, K. McKenna, M. Skoberne et al., "Endocytosis of HIV-1 activates plasmacytoid dendritic cells via Toll-like receptor-viral RNA interactions," Journal of Clinical Investigation, vol. 115, no. 11, pp. 3265-3275, 2005.

[13] M. Kader, A. P. Smith, C. Guiducci et al., "Blocking tlr7- and tlr9-mediated ifn-alpha production by plasmacytoid dendritic cells does not diminish immune activation in early siv infection," PLOS Pathogens, vol. 9, Article ID e1003530, 2013.

[14] A. Szabo and E. Rajnavolgyi, "Collaboration of toll-like and rigi-like receptors in human dendritic cells: triggering antiviral innate immune responses," American Journal of Clinical and Experimental Immunology, vol. 2, pp. 195-207, 2013.

[15] E. M. Creagh and L. A. J. O’Neill, "TLRs, NLRs and RLRs: a trinity of pathogen sensors that co-operate in innate immunity," Trends in Immunology, vol. 27, no. 8, pp. 352-357, 2006.

[16] O. Takeuchi and S. Akira, "Recognition of viruses by innate immunity," Immunological Reviews, vol. 220, no. 1, pp. 214-224, 2007.

[17] H. J. Ramos and M. Gale Jr., "RIG-I like receptors and their signaling crosstalk in the regulation of antiviral immunity," Current Opinion in Virology, vol. 1, no. 3, pp. 167-176, 2011.

[18] D. Goubau, S. Deddouche, and E. S. C. Reis, "Cytosolic sensing of viruses," Immunity, vol. 38, pp. 855-869, 2013.

[19] S. R. Paludan and A. G. Bowie, "Immune sensing of DNA," Immunity, vol. 38, pp. 870-880, 2013.

[20] T. Kawai and S. Akira, "Innate immune recognition of viral infection," Nature Immunology, vol. 7, no. 2, pp. 131-137, 2006.

[21] A. Boasso, A. W. Hardy, A. L. Landay et al., "PDL-1 upregulation on monocytes and T cells by HIV via type I interferon: restricted expression of type I interferon receptor by CCR5-expressing leukocytes," Clinical Immunology, vol. 129, no. 1, pp. 132-144, 2008.

[22] J.-F. Fonteneau, M. Larsson, A.-S. Beignon et al., "Human immunodeficiency virus type 1 activates plasmacytoid dendritic cells and concomitantly induces the bystander maturation of myeloid dendritic cells," Journal of Virology, vol. 78, no. 10, pp. 5223-5232, 2004.

[23] M. O’Brien, O. Manches, R. L. Sabado et al., "Spatiotemporal trafficking of HIV in human plasmacytoid dendritic cells defines a persistently IFN- $\alpha$-producing and partially matured phenotype," Journal of Clinical Investigation, vol. 121, no. 3, pp. 1088-1101, 2011.

[24] A. W. Hardy, D. R. Graham, G. M. Shearer, and J.-P. Herbeuval, "HIV turns plasmacytoid dendritic cells (pDC) into TRAILexpressing killer pDC and down-regulates HIV coreceptors by Toll-like receptor 7-induced IFN- $\alpha$," Proceedings of the National Academy of Sciences of the United States of America, vol. 104, no. 44, pp. 17453-17458, 2007.
[25] D. Harrich and B. Hooker, "Mechanistic aspects of HIV-1 reverse transcription initiation," Reviews in Medical Virology, vol. 12, no. 1, pp. 31-45, 2002.

[26] L. Kleiman, R. Halwani, and H. Javanbakht, "The selective packaging and annealing of primer tRNALys3 in HIV-1," Current HIV Research, vol. 2, no. 2, pp. 163-175, 2004.

[27] N. Arhel, "Revisiting HIV-1 uncoating," Retrovirology, vol. 7, article 96, 2010.

[28] M. Gilliet, W. Cao, and Y.-J. Liu, "Plasmacytoid dendritic cells: sensing nucleic acids in viral infection and autoimmune diseases," Nature Reviews Immunology, vol. 8, no. 8, pp. 594-606, 2008.

[29] S. Akira and K. Takeda, "Toll-like receptor signalling," Nature Reviews Immunology, vol. 4, no. 7, pp. 499-511, 2004.

[30] L. A. J. O’Neill, "How Toll-like receptors signal: what we know and what we don't know," Current Opinion in Immunology, vol. 18, no. 1, pp. 3-9, 2006.

[31] C. Guiducci, C. Ghirelli, M.-A. Marloie-Provost et al., "PI3K is critical for the nuclear translocation of IRF-7 and type I IFN production by human plasmacytoid predendritic cells in response to TLR activation," Journal of Experimental Medicine, vol. 205, no. 2, pp. 315-322, 2008.

[32] Y. Osawa, S. Iho, R. Takauji et al., "Collaborative action of NF$\kappa \mathrm{B}$ and $\mathrm{p} 38$ MAPK is involved in CpG DNA-induced IFN- $\alpha$ and chemokine production in human plasmacytoid dendritic cells," Journal of Immunology, vol. 177, no. 7, pp. 4841-4852, 2006.

[33] B. Baban, P. R. Chandler, B. A. Johnson III et al., "Physiologic control of IDO competence in splenic dendritic cells," Journal of Immunology, vol. 187, no. 5, pp. 2329-2335, 2011.

[34] A. K. Manlapat, D. J. Kahler, P. R. Chandler, D. H. Munn, and A. L. Mellor, "Cell-autonomous control of interferon type I expression by indoleamine 2, 3-dioxygenase in regulatory $\mathrm{CD} 19^{+}$ dendritic cells," European Journal of Immunology, vol. 37, no. 4, pp. 1064-1071, 2007.

[35] A. Boasso, J.-P. Herbeuval, A. W. Hardy et al., "HIV inhibits $\mathrm{CD}^{+}$T-cell proliferation by inducing indoleamine 2,3-dioxygenase in plasmacytoid dendritic cells," Blood, vol. 109, no. 8, pp. 3351-3359, 2007.

[36] B. Tavano, R. P. Galao, D. R. Graham et al., "Ig-like transcript 7, but not bone marrow stromal cell antigen 2 (also known as hm1. 24, tetherin, or cd317), modulates plasmacytoid dendritic cell function in primary human blood leukocytes," The Journal of Immunology, vol. 190, no. 6, pp. 2622-2630, 2013.

[37] P. Puccetti and U. Grohmann, "IDO and regulatory T cells: a role for reverse signalling and non-canonical NF- $\kappa$ B activation," Nature Reviews Immunology, vol. 7, no. 10, pp. 817-823, 2007.

[38] K. Hoshino, T. Sugiyama, M. Matsumoto et al., "I $\kappa \mathrm{B}$ kinase$\alpha$ is critical for interferon- $\alpha$ production induced by Toll-like receptors 7 and 9," Nature, vol. 440, no. 7086, pp. 949-953, 2006.

[39] C. Guiducci, G. Ott, J. H. Chan et al., "Properties regulating the nature of the plasmacytoid dendritic cell response to Toll-like receptor 9 activation," Journal of Experimental Medicine, vol. 203, no. 8, pp. 1999-2008, 2006.

[40] O. Takeuchi and S. Akira, "Pattern recognition receptors and inflammation," Cell, vol. 140, no. 6, pp. 805-820, 2010.

[41] R. K. Berg, J. Melchjorsen, J. Rintahaka et al., "Genomic HIV RNA induces innate immune responses through RIG-I-dependent sensing of secondary-structured RNA," PLoS ONE, vol. 7, no. 1, Article ID e29291, 2012.

[42] Y. Okabe, K. Kawane, S. Akira, T. Taniguchi, and S. Nagata, "Toll-like receptor-independent gene induction program activated by mammalian DNA escaped from apoptotic DNA 
degradation," Journal of Experimental Medicine, vol. 202, no. 10, pp. 1333-1339, 2005.

[43] V. Hornung, A. Ablasser, M. Charrel-Dennis et al., "AIM2 recognizes cytosolic dsDNA and forms a caspase-1-activating inflammasome with ASC," Nature, vol. 458, no. 7237, pp. 514-518, 2009.

[44] K. J. Ishii, C. Coban, H. Kato et al., "A toll-like receptor-independent antiviral response induced by double-stranded b-form DNA," Nature Immunology, vol. 7, pp. 40-48, 2006.

[45] S. Sharma, R. B. DeOliveira, P. Kalantari et al., "Innate immune recognition of an AT-rich stem-loop DNA motif in the plasmodium falciparum genome," Immunity, vol. 35, no. 2, pp. 194207, 2011.

[46] D. L. Burdette and R. E. Vance, "Sting and the innate immune response to nucleic acids in the cytosol," Nature Immunology, vol. 14, pp. 19-26, 2013.

[47] H. Ishikawa and G. N. Barber, "The STING pathway and regulation of innate immune signaling in response to DNA pathogens," Cellular and Molecular Life Sciences, vol. 68, no. 7, pp. 1157-1165, 2011.

[48] H. Ishikawa, Z. Ma, and G. N. Barber, "STING regulates intracellular DNA-mediated, type i interferon-dependent innate immunity," Nature, vol. 461, no. 7265, pp. 788-792, 2009.

[49] H. Ishikawa and G. N. Barber, "STING is an endoplasmic reticulum adaptor that facilitates innate immune signalling," Nature, vol. 455, no. 7213, pp. 674-678, 2008.

[50] Y. Tanaka and Z. J. Chen, "STING specifies IRF3 phosphorylation by TBK1 in the cytosolic DNA signaling pathway," Science Signaling, vol. 5, no. 214, article ra20, 2012.

[51] D. Gao, J. Wu, Y. T. Wu et al., "Cyclic gmp-amp synthase is an innate immune sensor of hiv and other retroviruses," Science, vol. 341, pp. 903-906, 2013.

[52] M. R. Jakobsen, R. O. Bak, A. Andersen et al., "Ifil6 senses DNA forms of the lentiviral replication cycle and controls hiv-1 replication," Proceedings of the National Academy of Sciences of the United States of America, vol. 110, no. 48, pp. E4571-E4580, 2013.

[53] M. Colonna, G. Trinchieri, and Y.-J. Liu, "Plasmacytoid dendritic cells in immunity," Nature Immunology, vol. 5, no. 12, pp. 1219-1226, 2004.

[54] A. G. Jegalian, F. Facchetti, and E. S. Jaffe, "Plasmacytoid dendritic cells physiologic roles and pathologic states," Advances in Anatomic Pathology, vol. 16, no. 6, pp. 392-404, 2009.

[55] J.-P. Herbeuval, A. W. Hardy, A. Boasso et al., "Regulation of TNF-related apoptosis-inducing ligand on primary $\mathrm{CD}^{+}$ T cells by HIV-1: role of type I IFN-producing plasmacytoid dendritic cells," Proceedings of the National Academy of Sciences of the United States of America, vol. 102, no. 39, pp. 13974-13979, 2005.

[56] E. Chertova, O. Chertov, L. V. Coren et al., "Proteomic and biochemical analysis of purified human immunodeficiency virus type 1 produced from infected monocyte-derived macrophages," Journal of Virology, vol. 80, no. 18, pp. 9039-9052, 2006.

[57] Z. Liao, J. W. Roos, and J. E. K. Hildreth, "Increased infectivity of HIV type 1 particles bound to cell surface and solid-phase ICAM-1 and VCAM-1 through acquired adhesion molecules LFA- 1 and VLA-4," AIDS Research and Human Retroviruses, vol. 16, no. 4, pp. 355-366, 2000.

[58] J. Arthos, C. Cicala, E. Martinelli et al., "HIV-1 envelope protein binds to and signals through integrin $\alpha 4 \beta 7$, the gut mucosal homing receptor for peripheral T cells," Nature Immunology, vol. 9, no. 3, pp. 301-309, 2008.
[59] M. E. Linde, D. R. Colquhoun, C. U. Mohien et al., “The conserved set of host proteins incorporated into hiv-1 virions suggests a common egress pathway in multiple cell types," Journal of Proteome Research, vol. 12, pp. 2045-2054, 2013.

[60] D. R. M. Graham, E. Chertova, J. M. Hilburn, L. O. Arthur, and J. E. K. Hildreth, "Cholesterol depletion of human immunodeficiency virus type 1 and simian immunodeficiency virus with $\beta$ cyclodextrin inactivates and permeabilizes the virions: evidence for virion-associated lipid rafts," Journal of Virology, vol. 77, no. 15, pp. 8237-8248, 2003.

[61] Z. Liao, D. R. Graham, and J. E. K. Hildreth, "Lipid rafts and HIV pathogenesis: virion-associated cholesterol is required for fusion and infection of susceptible cells," AIDS Research and Human Retroviruses, vol. 19, no. 8, pp. 675-687, 2003.

[62] Q. Li, J. D. Estes, P. M. Schlievert et al., "Glycerol monolaurate prevents mucosal SIV transmission," Nature, vol. 458, no. 7241, pp. 1034-1038, 2009.

[63] R. Lubong Sabado, M. O’Brien, A. Subedi et al., "Evidence of dysregulation of dendritic cells in primary HIV infection," Blood, vol. 116, no. 19, pp. 3839-3852, 2010.

[64] J.-P. Herbeuval, J. Nilsson, A. Boasso et al., "HAART reduces death ligand but not death receptors in lymphoid tissue of HIVinfected patients and simian immunodeficiency virus-infected macaques," AIDS, vol. 23, no. 1, pp. 35-40, 2009.

[65] J.-P. Herbeuval, J. Nilsson, A. Boasso et al., "Differential expression of IFN- $\alpha$ and TRAIL/DR5 in lymphoid tissue of progressor versus nonprogressor HIV-1-infected patients," Proceedings of the National Academy of Sciences of the United States of America, vol. 103, no. 18, pp. 7000-7005, 2006.

[66] M. Nascimbeni, L. Perié, L. Chorro et al., "Plasmacytoid dendritic cells accumulate in spleens from chronically HIV-infected patients but barely participate in interferon- $\alpha$ expression," Blood, vol. 113, no. 24, pp. 6112-6119, 2009.

[67] A. Benlahrech, A. Yasmin, S. J. Westrop et al., "Dysregulated immunophenotypic attributes of plasmacytoid but not myeloid dendritic cells in hiv-1 infected individuals in the absence of highly active anti-retroviral therapy," Clinical \& Experimental Immunology, vol. 170, pp. 212-221, 2012.

[68] O. Levy, E. E. Suter, R. L. Miller, and M. R. Wessels, "Unique efficacy of Toll-like receptor 8 agonists in activating human neonatal antigen-presenting cells," Blood, vol. 108, no. 4, pp. 1284-1290, 2006.

[69] V. J. Philbin and O. Levy, "Immunostimulatory activity of Tolllike receptor 8 agonists towards human leucocytes: basic mechanisms and translational opportunities," Biochemical Society Transactions, vol. 35, no. 6, pp. 1485-1491, 2007.

[70] V. Piguet and R. M. Steinman, "The interaction of HIV with dendritic cells: outcomes and pathways," Trends in Immunology, vol. 28, no. 11, pp. 503-510, 2007.

[71] K. Loré and M. Larsson, "The role of dendritic cells in the pathogenesis of HIV-1 infection," APMIS, vol. 111, no. 7-8, pp. 776-788, 2003.

[72] J. J. Mattapallil, D. C. Douek, B. Hill, Y. Nishimura, M. Martin, and M. Roederer, "Massive infection and loss of memory CD $4^{+}$ T cells in multiple tissues during acute SIV infection," Nature, vol. 434, no. 7037, pp. 1093-1097, 2005.

[73] J. M. Brenchley, T. W. Schacker, L. E. Ruff et al., "CD4 ${ }^{+}$T cell depletion during all stages of HIV disease occurs predominantly in the gastrointestinal tract," Journal of Experimental Medicine, vol. 200, no. 6, pp. 749-759, 2004. 
[74] L. J. Picker, "Immunopathogenesis of acute AIDS virus infection," Current Opinion in Immunology, vol. 18, no. 4, pp. 399405, 2006.

[75] L. Tarassishin, A. Bauman, H. S. Suh, and S. C. Lee, "Antiviral and anti-inflammatory mechanisms of the innate immune transcription factor interferon regulatory factor 3: relevance to human cns diseases," Journal of NeuroImmune Pharmacology, vol. 8, pp. 132-144, 2013.

[76] L. Pulliam, H. Rempel, B. Sun, L. Abadjian, C. Calosing, and D. J. Meyerhoff, "A peripheral monocyte interferon phenotype in HIV infection correlates with a decrease in magnetic resonance spectroscopy metabolite concentrations," AIDS, vol. 25, no. 14, pp. 1721-1726, 2011.

[77] J. Xu and T. Ikezu, "The comorbidity of HIV-associated neurocognitive disorders and alzheimer's disease: a foreseeable medical challenge in post-HAART era," Journal of Neuroimmune Pharmacology, vol. 4, no. 2, pp. 200-212, 2009.

[78] K. Grovit-Ferbas and M. E. Harris-White, "Thinking about HIV: the intersection of virus, neuroinflammation and cognitive dysfunction," Immunologic Research, vol. 48, no. 1-3, pp. 40-58, 2010.

[79] S. Gartner and Y. Liu, "Insights into the role of immune activation in HIV neuropathogenesis," Journal of NeuroVirology, vol. 8, no. 2, pp. 69-75, 2002.

[80] S. Tattermusch and C. R. Bangham, "Htlv-1 infection: what determines the risk of inflammatory disease?" Trends in Microbiology, vol. 20, pp. 494-500, 2012.

[81] S. Tattermusch, J. A. Skinner, D. Chaussabel et al., "Systems biology approaches reveal a specific interferon-inducible signature in HTLV-1 associated myelopathy," PLoS Pathogens, vol. 8, no. 1, Article ID e1002480, 2012.

[82] G. N. Barber, "Host defense, viruses and apoptosis," Cell Death and Differentiation, vol. 8, no. 2, pp. 113-126, 2001.

[83] J. Vilček, "Boosting p53 with interferon and viruses," Nature Immunology, vol. 4, no. 9, pp. 825-826, 2003.

[84] Y.-L. Chiu and W. C. Greene, "The APOBEC3 cytidine deaminases: an innate defensive network opposing exogenous retroviruses and endogenous retroelements," Annual Review of Immunology, vol. 26, pp. 317-353, 2008.

[85] S. J. D. Neil, V. Sandrin, W. I. Sundquist, and P. D. Bieniasz, "An interferon- $\alpha$-induced tethering mechanism inhibits HIV-1 and ebola virus particle release but is counteracted by the HIV-1 vpu protein," Cell Host and Microbe, vol. 2, no. 3, pp. 193-203, 2007.

[86] S. J. D. Neil, T. Zang, and P. D. Bieniasz, "Tetherin inhibits retrovirus release and is antagonized by HIV-1 vpu," Nature, vol. 451, no. 7177, pp. 425-430, 2008.

[87] G. Peng, J. L. Ke, W. Jin, T. Greenwell-Wild, and S. M. Wahl, "Induction of APOBEC3 family proteins, a defensive maneuver underlying interferon-induced anti-HIV-1 activity," Journal of Experimental Medicine, vol. 203, no. 1, pp. 41-46, 2006.

[88] P. M. Pitha, "Multiple effects of interferon on the replication of human immunodeficiency virus type 1," Antiviral Research, vol. 24, no. 2-3, pp. 205-219, 1994.

[89] K. M. Rose, M. Marin, S. L. Kozak, and D. Kabat, “Transcriptional regulation of APOBEC3G, a cytidine deaminase that hypermutates human immunodeficiency virus," The Journal of Biological Chemistry, vol. 279, no. 40, pp. 41744-41749, 2004.

[90] R. M. Steinman and H. Hemmi, "Dendritic cells: translating innate to adaptive immunity," Current Topics in Microbiology and Immunology, vol. 311, pp. 17-58, 2006.
[91] D. Novick, B. Cohen, and M. Rubinstein, "The human interferon $\alpha / \beta$ receptor: characterization and molecular cloning," Cell, vol. 77, no. 3, pp. 391-400, 1994.

[92] L. M. Pfeffer, L. Basu, S. R. Pfeffer et al., "The short form of the interferon $\alpha / \beta$ receptor chain 2 acts as a dominant negative for type I interferon action," The Journal of Biological Chemistry, vol. 272, no. 17, pp. 11002-11005, 1997.

[93] E. C. Cutrone and J. A. Langer, "Contributions of cloned type I interferon receptor subunits to differential ligand binding," FEBS Letters, vol. 404, no. 2-3, pp. 197-202, 1997.

[94] D. Russell-Harde, H. Pu, M. Betts, R. N. Harkins, H. D. Perez, and E. Croze, "Reconstitution of a high affinity binding site for type I interferons," The Journal of Biological Chemistry, vol. 270, no. 44, pp. 26033-26036, 1995.

[95] G. C. Sen, "Viruses and interferons," Annual Review of Microbiology, vol. 55, pp. 255-281, 2001.

[96] S. Matikainen, T. Sareneva, T. Ronni, A. Lehtonen, P. J. Koskinen, and I. Julkunen, "Interferon- $\alpha$ activates multiple STAT proteins and upregulates proliferation-associated IL-2R $\alpha, \mathrm{c}-\mathrm{myc}$, and pim-1 genes in human T cells," Blood, vol. 93, no. 6, pp. 1980-1991, 1999.

[97] E. Fasler-Kan, A. Pansky, M. Wiederkehr, M. Battegay, and M. H. Heim, "Interferon- $\alpha$ activates signal transducers and activators of transcription 5 and 6 in Daudi cells," European Journal of Biochemistry, vol. 254, no. 3, pp. 514-519, 1998.

[98] S. Goodbourn, L. Didcock, and R. E. Randall, "Interferons: cell signalling, immune modulation, antiviral responses and virus countermeasures," Journal of General Virology, vol. 81, no. 10, pp. 2341-2364, 2000.

[99] D. S. Aaronson and C. M. Horvath, "A road map for those who don't know JAK-STAT," Science, vol. 296, no. 5573, pp. 16531655, 2002.

[100] L. C. Platanias and E. N. Fish, "Signaling pathways activated by interferons," Experimental Hematology, vol. 27, no. 11, pp. 1583$1592,1999$.

[101] L. C. Platanias, "Mechanisms of type-I- and type-II-interferonmediated signalling," Nature Reviews Immunology, vol. 5, no. 5, pp. 375-386, 2005.

[102] M. Brucet, L. Marqués, C. Sebastián, J. Lloberas, and A. Celada, "Regulation of murine Tap1 and Lmp2 genes in macrophages by interferon gamma is mediated by STAT1 and IRF-1," Genes and Immunity, vol. 5, no. 1, pp. 26-35, 2004.

[103] M. L. Dustin, K. H. Singer, D. T. Tuck, and T. A. Springer, "Adhesion of T lymphoblasts to epidermal keratinocytes is regulated by interferon $\gamma$ and is mediated by intercellular adhesion molecule 1 (ICAM-1)," Journal of Experimental Medicine, vol. 167, no. 4, pp. 1323-1340, 1988.

[104] A. Yoshimura, "Signal transduction of inflammatory cytokines and tumor development," Cancer Science, vol. 97, no. 6, pp. 439447, 2006.

[105] T. Sato, C. Selleri, N. S. Young, and J. P. Maciejewski, "Inhibition of interferon regulatory factor-1 expression results in predominance of cell growth stimulatory effects of interferon- $\gamma$ due to phosphorylation of Stat1 and Stat3," Blood, vol. 90, no. 12, pp. 4749-4758, 1997.

[106] S. J. Baker, S. G. Rane, and E. P. Reddy, "Hematopoietic cytokine receptor signaling," Oncogene, vol. 26, no. 47, pp. 6724-6737, 2007.

[107] J. Azare, K. Leslie, H. Al-Ahmadie et al., "Constitutively activated stat 3 induces tumorigenesis and enhances cell motility of prostate epithelial cells through integrin $\beta 6$," Molecular and Cellular Biology, vol. 27, no. 12, pp. 4444-4453, 2007. 
[108] T. N. Dechow, L. Pedranzini, A. Leitch et al., "Requirement of matrix metalloproteinase-9 for the transformation of human mammary epithelial cells by Stat3-C," Proceedings of the National Academy of Sciences of the United States of America, vol. 101, no. 29, pp. 10602-10607, 2004.

[109] S. Ito, P. Ansari, M. Sakatsume et al., "Interleukin-10 inhibits expression of both interferon $\alpha$ - and interferon $\gamma$-induced genes by suppressing tyrosine phosphorylation of STAT1," Blood, vol. 93, no. 5, pp. 1456-1463, 1999.

[110] H. Wang, J. Brown, C. A. Garcia et al., "The role of glycogen synthase kinase 3 in regulating IFN- $\beta$-mediated IL-10 production," Journal of Immunology, vol. 186, no. 2, pp. 675-684, 2011.

[111] S. Kaur, A. Sassano, A. M. Joseph et al., "Dual regulatory roles of phosphatidylinositol 3-kinase in IFN signaling," Journal of Immunology, vol. 181, no. 10, pp. 7316-7323, 2008.

[112] F. Lekmine, A. Sassano, S. Uddin et al., "Interferon- $\gamma$ engages the p70 S6 kinase to regulate phosphorylation of the 40S S6 ribosomal protein," Experimental Cell Research, vol. 295, no. 1, pp. 173-182, 2004.

[113] F. Lekmine, S. Uddin, A. Sassano et al., "Activation of the p70 S6 kinase and phosphorylation of the 4E-BP1 repressor of mRNA translation by type I interferons," The Journal of Biological Chemistry, vol. 278, no. 30, pp. 27772-27780, 2003.

[114] Y. Li, A. Sassano, B. Majchrzak et al., "Role of p38 $\alpha$ map kinase in type I interferon signaling," The Journal of Biological Chemistry, vol. 279, no. 2, pp. 970-979, 2004.

[115] S. Uddin, F. Lekmine, N. Sharma et al., "The Rac1/p38 mitogenactivated protein kinase pathway is required for interferon $\alpha$ dependent transcriptional activation but not serine phosphorylation of Stat proteins," The Journal of Biological Chemistry, vol. 275, no. 36, pp. 27634-27640, 2000.

[116] S. Uddin, B. Majchrzak, J. Woodson et al., "Activation of the p38 mitogen-activated protein kinase by type I interferons," The Journal of Biological Chemistry, vol. 274, no. 42, pp. 30127-30131, 1999.

[117] M. David, E. Petricoin III, C. Benjamin, R. Pine, M. J. Weber, and A. C. Larner, "Requirement for MAP kinase (ERK2) activity in interferon $\alpha$ - and interferon $\beta$-stimulated gene expression through STAT proteins," Science, vol. 269, no. 5231, pp. 17211723, 1995.

[118] H. Ishida, K. Ohkawa, A. Hosui et al., "Involvement of p38 signaling pathway in interferon- $\alpha$-mediated antiviral activity toward hepatitis C virus," Biochemical and Biophysical Research Communications, vol. 321, no. 3, pp. 722-727, 2004.

[119] I. A. Mayer, A. Verma, I. M. Grumbach et al., “The p38 MAPK pathway mediates the growth inhibitory effects of interferon$\alpha$ in BCR-ABL-expressing cells," The Journal of Biological Chemistry, vol. 276, no. 30, pp. 28570-28577, 2001.

[120] F. Wang, Y. Ma, J. W. Barrett et al., "Disruption of Erk-dependent type I interferon induction breaks the myxoma virus species barrier," Nature Immunology, vol. 5, no. 12, pp. 12661274, 2004.

[121] J.-P. Herbeuval, A. Boasso, J.-C. Grivel et al., "TNF-related apoptosis-inducing ligand (TRAIL) in HIV-1-infected patients and its in vitro production by antigen-presenting cells," Blood, vol. 105, no. 6, pp. 2458-2464, 2005.

[122] J. J. Kohler, D. L. Tuttle, C. R. Coberley, J. W. Sleasman, and M. M. Goodenow, "Human immunodeficiency virus type 1 (HIV-1) induces activation of multiple stats in $\mathrm{CD}^{+}$cells of lymphocyte or monocyte/macrophage lineages," Journal of Leukocyte Biology, vol. 73, no. 3, pp. 407-416, 2003.
[123] B. Renga, D. Francisci, C. D’Amore et al., "The HIV matrix protein p17 subverts nuclear receptors expression and induces a STAT1-dependent proinflammatory phenotype in monocytes," PLoS ONE, vol. 7, no. 4, Article ID e35924, 2012.

[124] S. E. Bosinger, Q. Li, S. N. Gordon et al., "Global genomic analysis reveals rapid control of a robust innate response in SIVinfected sooty mangabeys," Journal of Clinical Investigation, vol. 119, no. 12, pp. 3556-3572, 2009.

[125] B. Jacquelin, V. Mayau, B. Targat et al., "Nonpathogenic SIV infection of African green monkeys induces a strong but rapidly controlled type I IFN response," Journal of Clinical Investigation, vol. 119, no. 12, pp. 3544-3555, 2009.

[126] N. K. Dhillon, F. Peng, R. M. Ransohoff, and S. Buch, "PDGF synergistically enhances IFN- $\gamma$-induced expression of CXCL10 in blood-derived macrophages: implications for HIV dementia," Journal of Immunology, vol. 179, no. 5, pp. 2722-2730, 2007.

[127] E. Masliah, E. S. Roberts, D. Langford et al., "Patterns of gene dysregulation in the frontal cortex of patients with HIV encephalitis," Journal of Neuroimmunology, vol. 157, no. 1-2, pp. 163-175, 2004.

[128] N. A. Khan, F. Di Cello, A. Nath, and K. S. Kim, "Human immunodeficiency virus type 1 Tat-mediated cytotoxicity of human brain microvascular endothelial cells," Journal of NeuroVirology, vol. 9, no. 6, pp. 584-593, 2003.

[129] R. L. Furler and C. H. Uittenbogaart, "Signaling through the P38 and ERK pathways: a common link between HIV replication and the immune response," Immunologic Research, vol. 48, no. 1-3, pp. 99-109, 2010.

[130] D. Gutierrez-Sanmartin, E. Varela-Ledo, A. Aguilera et al., "Implication of p38 mitogen-activated protein kinase isoforms $(\alpha, \beta, \gamma$ and $\delta)$ in $\mathrm{CD}^{+}$T-cell infection with human immunodeficiency virus type 1," Journal of General Virology, vol. 89, no. 7, pp. 1661-1671, 2008.

[131] R. Horie, T. Ishida, M. Maruyama-Nagai et al., "TRAF activation of C/EBP $\beta$ (NF-IL6) via p38 MAPK induces HIV-1 gene expression in monocytes/macrophages," Microbes and Infection, vol. 9, no. 6, pp. 721-728, 2007.

[132] K. Muthumani, S. A. Wadsworth, N. S. Dayes et al., "Suppression of HIV-1 viral replication and cellular pathogenesis by a novel p38/JNK kinase inhibitor," AIDS, vol. 18, no. 5, pp. 739$748,2004$.

[133] L. Shapiro, K. A. Heidenreich, M. K. Meintzer, and C. A. Dinarello, "Role of p38 mitogen-activated protein kinase in HIV type 1 production in vitro," Proceedings of the National Academy of Sciences of the United States of America, vol. 95, no. 13, pp. 7422-7426, 1998.

[134] P. S. Cohen, H. Schmidtmayerova, J. Dennis et al., "The critical role of p38 MAP kinase in T cell HIV-1 replication," Molecular Medicine, vol. 3, no. 5, pp. 339-346, 1997.

[135] S. Kumar, M. J. Orsini, J. C. Lee, P. C. McDonnell, C. Debouck, and P. R. Young, "Activation of the HIV-1 long terminal repeat by cytokines and environmental stress requires an active CSBP/p38 MAP kinase," The Journal of Biological Chemistry, vol. 271, no. 48, pp. 30864-30869, 1996.

[136] E. Jacotot, B. Krust, C. Callebaut, A. G. Laurent-Crawford, J. Blanco, and A. G. Hovanessian, "HIV-1 envelope glycoproteinsmediated apoptosis is regulated by CD4 dependent and independent mechanisms," Apoptosis, vol. 2, no. 1, pp. 47-60, 1997.

[137] M. Kaul and S. A. Lipton, "Chemokines and activated macrophages in HIV gp120-induced neuronal apoptosis," Proceedings of the National Academy of Sciences of the United States of America, vol. 96, no. 14, pp. 8212-8216, 1999. 
[138] C. E. Rudd, "MARK p38: alternative and nonstressful in T cells," Nature Immunology, vol. 6, no. 4, pp. 368-370, 2005.

[139] S. A. Trushin, A. Algeciras-Schimnich, S. R. Vlahakis et al., "Glycoprotein 120 binding to CXCR4 causes p38-dependent primary $\mathrm{T}$ cell death that is facilitated by, but does not require cell-associated CD4," Journal of Immunology, vol. 178, no. 8, pp. 4846-4853, 2007.

[140] A. Boasso, A. W. Hardy, S. A. Anderson, M. J. Dolan, and G. M. Shearer, "HIV-induced type I interferon and tryptophan catabolism drive $\mathrm{T}$ cell dysfunction despite phenotypic activation," PLoS ONE, vol. 3, no. 8, Article ID e2961, 2008.

[141] X. Yang, Y. M. Jiao, R. Wang et al., "High ccr5 density on central memory $\mathrm{cd} 4^{+}$t cells in acute hiv-1 infection is mostly associated with rapid disease progression," PLoS ONE, vol. 7, Article ID e49526, 2012.

[142] M. Paiardini, B. Cervasi, E. Reyes-Aviles et al., "Low levels of SIV infection in sooty mangabey central memory CD $4^{+} \mathrm{T}$ cells are associated with limited CCR5 expression," Nature Medicine, vol. 17, no. 7, pp. 830-836, 2011.

[143] I. Pandrea, C. Apetrei, S. Gordon et al., "Paucity of CD $4^{+}$CCR5 ${ }^{+}$ T cells is a typical feature of natural SIV hosts," Blood, vol. 109, no. 3, pp. 1069-1076, 2007.

[144] K. Fukada, Y. Sobao, H. Tomiyama, S. Oka, and M. Takiguchi, "Functional expression of the chemokine receptor CCR5 on virus epitope-specific memory and effector CD8 ${ }^{+} \mathrm{T}$ cells," Journal of Immunology, vol. 168, no. 5, pp. 2225-2232, 2002.

[145] I. Pandrea, R. Onanga, S. Souquiere et al., "Paucity of CD4 ${ }^{+}$ $\mathrm{CCR}^{+} \mathrm{T}$ cells may prevent transmission of simian immunodeficiency virus in natural nonhuman primate hosts by breastfeeding," Journal of Virology, vol. 82, no. 11, pp. 5501-5509, 2008.

[146] J.-P. Herbeuval and G. M. Shearer, "HIV-1 immunopathogenesis: how good interferon turns bad," Clinical Immunology, vol. 123, no. 2, pp. 121-128, 2007.

[147] M. Chawla-Sarkar, D. J. Lindner, Y.-F. Liu et al., "Apoptosis and interferons: role of interferon-stimulated genes as mediators of apoptosis," Apoptosis, vol. 8, no. 3, pp. 237-249, 2003.

[148] H. Tamura, K. Ogata, H. Dong, and L. Chen, "Immunology of B7-H1 and its roles in human diseases," International Journal of Hematology, vol. 78, no. 4, pp. 321-328, 2003.

[149] A. D. Badley, D. H. Dockrell, A. Algeciras et al., "In vivo analysis of Fas/FasL interactions in HIV-infected patients," Journal of Clinical Investigation, vol. 102, no. 1, pp. 79-87, 1998.

[150] A. M. Dyrhol-Riise, M. Ohlsson, K. Skarstein et al., "T cell proliferation and apoptosis in HIV-1-infected lymphoid tissue: impact of highly active antiretroviral therapy," Clinical Immunology, vol. 101, no. 2, pp. 180-191, 2001.

[151] A. M. Dyrhol-Riise, G. Stent, B. I. Røsok, P. Voltersvik, J. Olofsson, and B. Åsjö, "The Fas/FasL system and T cell apoptosis in HIV-1-infected lymphoid tissue during highly active antiretroviral therapy," Clinical Immunology, vol. 101, no. 2, pp. 169-179, 2001.

[152] J.-P. Herbeuval, J.-C. Grivel, A. Boasso et al., "CD4 ${ }^{+}$T-cell death induced by infectious and noninfectious HIV-1: role of type 1 interferon-dependent, TRAIL/DR5-mediated apoptosis," Blood, vol. 106, no. 10, pp. 3524-3531, 2005.

[153] G. Stary, I. Klein, S. Kohlhofer et al., "Plasmacytoid dendritic cells express TRAIL and induce CD4 ${ }^{+}$T-cell apoptosis in HIV1 viremic patients," Blood, vol. 114, no. 18, pp. 3854-3863, 2009.

[154] J.-P. Herbeuval, C. Lambert, O. Sabido et al., "Macrophages from cancer patients: analysis of TRAIL, TRAIL receptors, and colon tumor cell apoptosis," Journal of the National Cancer Institute, vol. 95, no. 8, pp. 611-621, 2003.
[155] J. Chehimi, E. Papasavvas, C. Tomescu et al., "Inability of plasmacytoid dendritic cells to directly lyse HIV-infected autologous $\mathrm{CD} 4^{+} \mathrm{T}$ cells despite induction of tumor necrosis factorrelated apoptosis-inducing ligand," Journal of Virology, vol. 84, no. 6, pp. 2762-2773, 2010.

[156] D.-M. Zhu, J. Shi, S. Liu, Y. Liu, and D. Zheng, "HIV infection enhances TRAIL-induced cell death in macrophage by downregulating decoy receptor expression and generation of reactive oxygen species," PLoS ONE, vol. 6, no. 4, Article ID e18291, 2011.

[157] D. Trabattoni, M. Saresella, M. Biasin et al., "B7-H1 is upregulated in HIV infection and is a novel surrogate marker of disease progression," Blood, vol. 101, no. 7, pp. 2514-2520, 2003.

[158] L. V. Riella, A. M. Paterson, A. H. Sharpe, and A. Chandraker, "Role of the pd-1 pathway in the immune response," American Journal of Transplantation, vol. 12, pp. 2575-2587, 2012.

[159] M. Larsson, E. M. Shankar, K. F. Che et al., "Molecular signatures of t-cell inhibition in hiv-1 infection," Retrovirology, vol. 10, article 31, 2013.

[160] B. E. Palmer, C. P. Neff, J. Lecureux et al., "In vivo blockade of the pd-1 receptor suppresses hiv-1 viral loads and improves $\mathrm{cd} 4^{+}$ $\mathrm{t}$ cell levels in humanized mice," The Journal of Immunology, vol. 190, pp. 211-219, 2013.

[161] B. Dai, L. Xiao, P. D. Bryson, J. Fang, and P. Wang :, "Pd1/pd-l1 blockade can enhance hiv-1 gag-specific $t$ cell immunity elicited by dendritic cell-directed lentiviral vaccines," Molecular Therapy, vol. 20, pp. 1800-1809, 2012.

[162] R. D. Shetty, V. Velu, K. Titanji et al., "PD-1 blockade during chronic SIV infection reduces hyperimmune activation and microbial translocation in rhesus macaques," Journal of Clinical Investigation, vol. 122, no. 5, pp. 1712-1716, 2012.

[163] F. Porichis, D. S. Kwon, J. Zupkosky et al., "Responsiveness of HIV-specific CD4 T cells to PD-1 blockade," Blood, vol. 118, no. 4, pp. 965-974, 2011.

[164] B. J. Macatangay and C. R. Rinaldo, "Pd-1 blockade: a promising immunotherapy for hiv?” Cellscience, vol. 5, pp. 61-65, 2009.

[165] A. Takaoka, S. Hayakawa, H. Yanai et al., "Integration of interferon- $\alpha / \beta$ signalling to $\mathrm{p} 53$ responses in tumour suppression and antiviral defence," Nature, vol. 424, no. 6948, pp. 516523, 2003.

[166] G. Doitsh, M. Cavrois, K. G. Lassen et al., "Abortive HIV infection mediates CD4 T cell depletion and inflammation in human lymphoid tissue," Cell, vol. 143, no. 5, pp. 789-801, 2010.

[167] A. J. Sadler and B. R. G. Williams, "Interferon-inducible antiviral effectors," Nature Reviews Immunology, vol. 8, no. 7, pp. 559-568, 2008.

[168] T. Takeuchi, S. Iwahara, Y. Saeki, H. Sasajima, and H. Yokosawa, "Link between the ubiquitin conjugation system and the ISG15 conjugation system: ISG15 conjugation to the UbcH6 ubiquitin E2 enzyme," Journal of Biochemistry, vol. 138, no. 6, pp. 711-719, 2005.

[169] C. Zhao, S. L. Beaudenon, M. L. Kelley et al., "The UbcH8 ubiquitin E2 enzyme is also the E2 enzyme for ISG15, an IFN$\alpha / \beta$-induced ubiquitin-like protein," Proceedings of the National Academy of Sciences of the United States of America, vol. 101, no. 20, pp. 7578-7582, 2004.

[170] W. Yuan and R. M. Krug, "Influenza B virus NS1 protein inhibits conjugation of the interferon (IFN)-induced ubiquitin-like ISG15 protein," The EMBO Journal, vol. 20, no. 3, pp. 362-371, 2001.

[171] G. Lu, J. T. Reinert, I. Pitha-Rowe et al., "ISG15 enhances the innate antiviral response by inhibition of IRF-3 degradation," Cellular and Molecular Biology, vol. 52, no. 1, pp. 29-41, 2006. 
[172] T. Takeuchi, T. Kobayashi, S. Tamura, and H. Yokosawa, "Negative regulation of protein phosphatase $2 \mathrm{C} \beta$ by ISG15 conjugation," FEBS Letters, vol. 580, no. 18, pp. 4521-4526, 2006.

[173] M. W. Woods, J. N. Kelly, C. J. Hattlmann et al., "Human HERC5 restricts an early stage of HIV-1 assembly by a mechanism correlating with the ISGylation of Gag," Retrovirology, vol. 8, article 95, 2011.

[174] A. Okumura, G. Lu, I. Pitha-Rowe, and P. M. Pitha, "Innate antiviral response targets HIV-1 release by the induction of ubiquitin-like protein ISG15," Proceedings of the National Academy of Sciences of the United States of America, vol. 103, no. 5, pp. 1440-1445, 2006.

[175] J. D. MacMicking, "IFN-inducible GTPases and immunity to intracellular pathogens," Trends in Immunology, vol. 25, no. 11, pp. 601-609, 2004.

[176] O. Haller, H. Arnheiter, J. Lindenmann, and I. Gresser, "Host gene influences sensitivity to interferon action selectively for influenza virus," Nature, vol. 283, no. 5748, pp. 660-662, 1980.

[177] C. Goujon, O. Moncorge, H. Bauby et al., "Human $\mathrm{mx2}$ is an interferon-induced post-entry inhibitor of hiv-1 infection," Nature, vol. 502, pp. 559-562, 2013.

[178] Z. Liu, Q. Pan, S. Ding et al., "The interferon-inducible mxb protein inhibits hiv-1 infection," Cell Host \& Microbe, vol. 14, pp. 398-410, 2013.

[179] D. Rebouillat and A. G. Hovanessian, “The human 2',5'-oligoadenylate synthetase family: interferon-induced proteins with unique enzymatic properties," Journal of Interferon and Cytokine Research, vol. 19, no. 4, pp. 295-308, 1999.

[180] I. M. Kerr, R. E. Brown, and A. G. Hovanessian, "Nature of inhibitor of cell-free protein synthesis formed in response to interferon and double-stranded RNA," Nature, vol. 268, no. 5620, pp. 540-542, 1977.

[181] M. J. Clemens and C. M. Vaquero, "Inhibition of protein synthesis by double-stranded RNA in reticulocyte lysates: evidence for activation of an endoribonuclease," Biochemical and Biophysical Research Communications, vol. 83, no. 1, pp. 59-68, 1978.

[182] K. Malathi, B. Dong, M. Gale Jr., and R. H. Silverman, "Small self-RNA generated by RNase L amplifies antiviral innate immunity," Nature, vol. 448, no. 7155, pp. 816-819, 2007.

[183] R. K. Maitra and R. H. Silverman, "Regulation of human immunodeficiency virus replication by $2^{\prime}, 5^{\prime}$ - oligoadenylate-dependent RNase L," Journal of Virology, vol. 72, no. 2, pp. 1146-1152, 1998.

[184] W. K. Roberts, A. Hovanessian, and R. E. Brown, "Interferon mediated protein kinase and low molecular weight inhibitor of protein synthesis," Nature, vol. 264, no. 5585, pp. 477-480, 1976.

[185] D. R. Taylor, S. B. Lee, P. R. Romano et al., "Autophosphorylation sites participate in the activation of the double- stranded-RNAactivated protein kinase PKR," Molecular and Cellular Biology, vol. 16, no. 11, pp. 6295-6302, 1996.

[186] P. R. Romano, M. T. Garcia-Barrio, X. Zhang et al., "Autophosphorylation in the activation loop is required for full kinase activity in vivo of human and yeast eukaryotic initiation factor $2 \alpha$ kinases PKR and GCN2," Molecular and Cellular Biology, vol. 18, no. 4, pp. 2282-2297, 1998.

[187] M. Dey, C. Cao, A. C. Dar et al., "Mechanistic link between PKR dimerization, autophosphorylation, and eIF $2 \alpha$ substrate recognition," Cell, vol. 122, no. 6, pp. 901-913, 2005.

[188] A. C. Dar, T. E. Dever, and F. Sicheri, "Higher-order substrate recognition of eIF $2 \alpha$ by the RNA-dependent protein kinase PKR," Cell, vol. 122, no. 6, pp. 887-900, 2005.
[189] S. Nanduri, B. W. Carpick, Y. Yang, B. R. G. Williams, and J. Qin, "Structure of the double-stranded RNA-binding domain of the protein kinase PKR reveals the molecular basis of its dsRNA-mediated activation," The EMBO Journal, vol. 17, no. 18, pp. 5458-5465, 1998.

[190] S. R. Nallagatla, J. Hwang, R. Toroney, X. Zheng, C. E. Cameron, and P. C. Bevilacqua, " 5 '-triphosphate-dependent activation of PKR by RNAs with short stem-loops," Science, vol. 318, no. 5855, pp. 1455-1458, 2007.

[191] M. E. Adelson, C. Martinand-Mari, K. T. Iacono, N. F. Muto, and R. J. Suhadolnik, "Inhibition of human immunodeficiency virus (HIV-1) replication in SupT1 cells transduced with an HIV-1 LTR-driven PKR cDNA construct," European Journal of Biochemistry, vol. 264, no. 3, pp. 806-815, 1999.

[192] G. Clerzius, J.-F. Gélinas, A. Daher, M. Bonnet, E. F. Meurs, and A. Gatignol, "ADAR1 interacts with PKR during human immunodeficiency virus infection of lymphocytes and contributes to viral replication," Journal of Virology, vol. 83, no. 19, pp. 1011910128, 2009.

[193] D. I. Dimitrova, X. Yang, N. L. Reichenbach et al., "Lentivirusmediated transduction of PKR into CD $34^{+}$hematopoietic stem cells inhibits HIV-1 replication in differentiated T cell progeny," Journal of Interferon and Cytokine Research, vol. 25, no. 6, pp. 345-360, 2005.

[194] A. Daher, M. Longuet, D. Dorin et al., "Two dimerization domains in the trans-activation response RNA-binding protein (TRBP) individually reverse the protein kinase $\mathrm{R}$ inhibition of HIV-1 long terminal repeat expression," The Journal of Biological Chemistry, vol. 276, no. 36, pp. 33899-33905, 2001.

[195] M. Benkirane, C. Neuveut, R. F. Chun et al., "Oncogenic potential of TAR RNA binding protein TRBP and its regulatory interaction with RNA-dependent protein kinase PKR," The EMBO Journal, vol. 16, no. 3, pp. 611-624, 1997.

[196] N. F. Muto, C. Martinand-Mari, M. E. Adelson, and R. J. Suhadolnik, "Inhibition of replication of reactivated human immunodeficiency virus type 1 (HIV-1) in latently infected U1 cells transduced with an HIV-1 long terminal repeat-driven PKR cDNA construct," Journal of Virology, vol. 73, no. 11, pp. 90219028, 1999.

[197] S. Bannwarth and A. Gatignol, "HIV-1 TAR RNA: the target of molecular interactions between the virus and its host," Current HIV Research, vol. 3, no. 1, pp. 61-71, 2005.

[198] D. Dorin, M. C. Bonnet, S. Bannwarth, A. Gatignol, E. F. Meurs, and C. Vaquero, "The TAR RNA-binding protein, TRBP, stimulates the expression of TAR-containing RNAs in vitro and in vivo independently of its ability to inhibit the dsRNAdependent kinase PKR," The Journal of Biological Chemistry, vol. 278, no. 7, pp. 4440-4448, 2003.

[199] A. Gatignol, "Transcription of HIV: tat and cellular chromatin," Advances in Pharmacology, vol. 55, pp. 137-159, 2007.

[200] B. W. Carpick, V. Graziano, D. Schneider, R. K. Maitra, X. Lee, and B. R. G. Williams, "Characterization of the solution complex between the interferon-induced, double-stranded RNAactivated protein kinase and HIV-I trans-activating region RNA," The Journal of Biological Chemistry, vol. 272, no. 14, pp. 9510-9516, 1997.

[201] I. Kim, C. W. Liu, and J. D. Puglisi, "Specific Recognition of HIV TAR RNA by the dsRNA Binding Domains (dsRBD1-dsRBD2) of PKR," Journal of Molecular Biology, vol. 358, no. 2, pp. 430442, 2006. 
[202] R. K. Maitra, N. A. J. McMillan, S. Desai et al., "HIV-1 TAR RNA has an intrinsic ability to activate interferon-inducible enzymes," Virology, vol. 204, no. 2, pp. 823-827, 1994.

[203] A. Reymond, G. Meroni, A. Fantozzi et al., "The tripartite motif family identifies cell compartments," The EMBO Journal, vol. 20, no. 9, pp. 2140-2151, 2001.

[204] S. D. Barr, J. R. Smiley, and F. D. Bushman, "The interferon response inhibits HIV particle production by induction of TRIM22," PLoS Pathogens, vol. 4, no. 2, 2008.

[205] M. Stremlau, C. M. Owens, M. J. Perron, M. Kiessling, P. Autissier, and J. Sodroski, "The cytoplasmic body component TRIM $5 \alpha$ restricts HIV-1 infection in old world monkeys," Nature, vol. 427, no. 6977, pp. 848-853, 2004.

[206] M. W. Yap, S. Nisole, C. Lynch, and J. P. Stoye, “TRIM5 $\alpha$ protein restricts both HIV-1 and murine leukemia virus," Proceedings of the National Academy of Sciences of the United States of America, vol. 101, no. 29, pp. 10786-10791, 2004.

[207] M. G. Grütter and J. Luban, "TRIM5 structure, HIV-1 capsid recognition, and innate immune signaling," Current Opinion in Virology, vol. 2, no. 2, pp. 142-150, 2012.

[208] L. Carthagena, A. Bergamaschi, J. M. Luna et al., "Human TRIM gene expression in response to interferons," PLoS ONE, vol. 4, no. 3, Article ID e4894, 2009.

[209] J. Luban, "Cyclophilin A, TRIM5, and resistance to human immunodeficiency virus type 1 infection," Journal of Virology, vol. 81, no. 3, pp. 1054-1061, 2007.

[210] M. Lienlaf, F. Hayashi, F. Di Nunzio et al., "Contribution of E3-ubiquitin ligase activity to HIV-1 restriction by TRIM $\alpha \alpha \mathrm{rh}$ : structure of the RING domain of TRIM5 $\alpha$, Journal of Virology, vol. 85, no. 17, pp. 8725-8737, 2011.

[211] T. Pertel, S. Hausmann, D. Morger et al., "TRIM5 is an innate immune sensor for the retrovirus capsid lattice," Nature, vol. 472, no. 7343, pp. 361-365, 2011.

[212] C. O’Connor, T. Pertel, S. Gray et al., "p62/sequestosome-1 associates with and sustains the expression of retroviral restriction factor TRIM5 $\alpha$, Journal of Virology, vol. 84, no. 12, pp. 5997-6006, 2010.

[213] C. J. Rold and C. Aiken, "Proteasomal degradation of TRIM5 $\alpha$ during retrovirus restriction," PLoS Pathogens, vol. 4, no. 5, Article ID e1000074, 2008.

[214] Z. Lukic, S. Hausmann, S. Sebastian et al., "TRIM5alpha associates with proteasomal subunits in cells while in complex with HIV-1 virions," Retrovirology, vol. 8, article 93, 2011.

[215] A. J. Price, F. Marzetta, M. Lammers et al., "Active site remodeling switches HIV specificity of antiretroviral TRIMCyp," Nature Structural and Molecular Biology, vol. 16, no. 10, pp. 1036-1042, 2009.

[216] G. J. Towers, T. Hatziioannou, S. Cowan, S. P. Goff, J. Luban, and P. D. Bieniasz, "Cyclophilin A modulates the sensitivity of HIV1 to host restriction factors," Nature Medicine, vol. 9, no. 9, pp. 1138-1143, 2003.

[217] W. Hofmann, D. Schubert, J. LaBonte et al., "Species-specific, postentry barriers to primate immunodeficiency virus infection," Journal of Virology, vol. 73, no. 12, pp. 10020-10028, 1999.

[218] M. Stremlau, M. Perron, M. Lee et al., "Specific recognition and accelerated uncoating of retroviral capsids by the TRIM5 $\alpha$ restriction factor," Proceedings of the National Academy of Sciences of the United States of America, vol. 103, no. 14, pp. 55145519, 2006.

[219] E. Sokolskaja, L. Berthoux, and J. Luban, "Cyclophilin A and TRIM $5 \alpha$ independently regulate human immunodeficiency virus type 1 infectivity in human cells," Journal of Virology, vol. 80, no. 6, pp. 2855-2862, 2006.

[220] E. Battivelli, D. Lecossier, S. Matsuoka, J. Migraine, F. Clavel, and A. J. Hance, "Strain-specific differences in the impact of human TRIM $5 \alpha$, different TRIM $5 \alpha$ alleles, and the inhibition of capsidcyclophilin a interactions on the infectivity of HIV-1," Journal of Virology, vol. 84, no. 21, pp. 11010-11019, 2010.

[221] A. Kirmaier, F. Wu, R. M. Newman et al., "TRIM5 suppresses cross-species transmission of a primate immunodeficiency virus and selects for emergence of resistant variants in the new species," PLoS Biology, vol. 8, no. 8, pp. 35-36, 2010.

[222] S.-Y. Lim, T. Chan, R. S. Gelman et al., "Contributions of Mamu$A^{*} 01$ status and TRIM5 allele expression, but not CCL3L copy number variation, to the control of SIVmac251 replication in Indian-origin rhesus monkeys," PLoS genetics, vol. 6, no. 6, p. e1000997, 2010.

[223] S.-Y. Lim, T. Rogers, T. Chan et al., "TRIM5 $\alpha$ modulates immunodeficiency virus control in rhesus monkeys," PLoS Pathogens, vol. 6, no. 1, Article ID e1000738, 2010.

[224] M. R. Reynolds, J. B. Sacha, A. M. Weiler et al., “The TRIM5 $\alpha$ genotype of rhesus macaques affects acquisition of simian immunodeficiency virus SIVsmE660 infection after repeated limiting-dose intrarectal challenge," Journal of Virology, vol. 85, no. 18, pp. 9637-9640, 2011.

[225] W. W. Yeh, S. S. Rao, S.-Y. Lim et al., "The TRIM5 gene modulates penile mucosal acquisition of simian immunodeficiency virus in rhesus monkeys," Journal of Virology, vol. 85, no. 19, pp. 10389-10398, 2011.

[226] F.-L. Liu, Y.-Q. Qiu, H. Li et al., "An HIV-1 resistance polymorphism in TRIM5 $\alpha$ gene among Chinese intravenous drug users," Journal of Acquired Immune Deficiency Syndromes, vol. 56, no. 4, pp. 306-311, 2011.

[227] H. Price, P. Lacap, J. Tuff et al., "A TRIM5 $\alpha$ exon 2 polymorphism is associated with protection from HIV-1 infection in the Pumwani sex worker cohort," AIDS, vol. 24, no. 12, pp. 18131821, 2010.

[228] S. Sewram, R. Singh, E. Kormuth et al., "Human TRIM5 $\alpha$ expression levels and reduced susceptibility to HIV-I infection," Journal of Infectious Diseases, vol. 199, no. 11, pp. 1657-1663, 2009.

[229] D. Van Manen, M. A. N. Rits, C. Beugeling, K. Van Dort, H. Schuitemaker, and N. A. Kootstra, "The effect of TRIM5 polymorphisms on the clinical course of HIV-1 infection," PLoS Pathogens, vol. 4, no. 2, 2008.

[230] E. Battivelli, J. Migraine, D. Lecossier, P. Yeni, F. Clavel, and A. J. Hance, "Gag cytotoxic T lymphocyte escape mutations can increase sensitivity of HIV-1 to human TRIM5 $\alpha$, linking intrinsic and acquired immunity," Journal of Virology, vol. 85, no. 22, pp. 11846-11854, 2011.

[231] S. U. Tareen and M. Emerman, "Human TRIM5 $\alpha$ has additional activities that are uncoupled from retroviral capsid recognition," Virology, vol. 409, no. 1, pp. 113-120, 2011.

[232] A. Bouazzaoui, M. Kreutz, V. Eisert et al., "Stimulated transacting factor of $50 \mathrm{kDa}$ (Staf50) inhibits HIV-1 replication in human monocyte-derived macrophages," Virology, vol. 356, no. 1-2, pp. 79-94, 2006.

[233] C. Tissot and N. Mechti, "Molecular cloning of a new interferoninduced factor that represses human immunodeficiency virus type I long terminal repeat expression," The Journal of Biological Chemistry, vol. 270, no. 25, pp. 14891-14898, 1995.

[234] A. Kajaste-Rudnitski, S. S. Marelli, C. Pultrone et al., “TRIM22 inhibits HIV-1 transcription independently of Its E3 ubiquitin 
ligase activity, Tat, and NF- $\kappa$ B-responsive long terminal repeat elements," Journal of Virology, vol. 85, no. 10, pp. 5183-5196, 2011.

[235] A. M. Sheehy, N. C. Gaddis, J. D. Choi, and M. H. Malim, "Isolation of a human gene that inhibits HIV-1 infection and is suppressed by the viral Vif protein," Nature, vol. 418, no. 6898, pp. 646-650, 2002.

[236] L. Chelico, P. Pham, P. Calabrese, and M. F. Goodman, "APOBEC3G DNA deaminase acts processively $3^{\prime} \rightarrow 5^{\prime}$ on single-stranded DNA," Nature Structural and Molecular Biology, vol. 13, no. 5, pp. 392-399, 2006.

[237] R. S. Harris, K. N. Bishop, A. M. Sheehy et al., "DNA deamination mediates innate immunity to retroviral infection," Cell, vol. 113, no. 6, pp. 803-809, 2003.

[238] Q. Yu, R. König, S. Pillai et al., "Single-strand specificity of APOBEC3G accounts for minus-strand deamination of the HIV genome," Nature Structural and Molecular Biology, vol. 11, no. 5, pp. 435-442, 2004.

[239] M.-A. Langlois and M. S. Neuberger, "Human APOBEC3G can restrict retroviral infection in avian cells and acts independently of both UNG and SMUG1," Journal of Virology, vol. 82, no. 9, pp. 4660-4664, 2008.

[240] K. N. Bishop, M. Verma, E.-Y. Kim, S. M. Wolinsky, and M. H. Malim, "APOBEC3G inhibits elongation of HIV-1 reverse transcripts," PLoS Pathogens, vol. 4, no. 12, Article ID e1000231, 2008.

[241] Y. Iwatani, D. S. B. Chan, F. Wang et al., "Deaminase-independent inhibition of HIV-1 reverse transcription by APOBEC3G," Nucleic Acids Research, vol. 35, no. 21, pp. 7096-7108, 2007.

[242] H. P. Bogerd and B. R. Cullen, "Single-stranded RNA facilitates nucleocapsid: APOBEC3G complex formation," RNA, vol. 14, no. 6, pp. 1228-1236, 2008.

[243] B. Mangeat, P. Turelli, G. Caron, M. Friedli, L. Perrin, and D. Trono, "Broad antiretroviral defence by human APOBEC3G through lethal editing of nascent reverse transcripts," Nature, vol. 424, no. 6944, pp. 99-103, 2003.

[244] X. Yu, Y. Yu, B. Liu et al., "Induction of APOBEC3G ubiquitination and degradation by an HIV-1 Vif-Cul5-SCF complex," Science, vol. 302, no. 5647, pp. 1056-1060, 2003.

[245] H. Zhang, B. Yang, R. J. Pomerantz, C. Zhang, S. C. Arunachalam, and L. Gao, "The cytidine deaminase CEM15 induces hypermutation in newly synthesized HIV-1 DNA," Nature, vol. 424, no. 6944, pp. 94-98, 2003.

[246] M. Marin, K. M. Rose, S. L. Kozak, and D. Kabat, "HIV-1 Vif protein binds the editing enzyme APOBEC $3 \mathrm{G}$ and induces its degradation," Nature Medicine, vol. 9, no. 11, pp. 1398-1403, 2003.

[247] A. M. Sheehy, N. C. Gaddis, and M. H. Malim, "The antiretroviral enzyme APOBEC3G is degraded by the proteasome in response to HIV-1 Vif," Nature Medicine, vol. 9, no. 11, pp. 14041407, 2003.

[248] K. Stopak, C. De Noronha, W. Yonemoto, and W. C. Greene, "HIV-1 Vif blocks the antiviral activity of APOBEC3G by impairing both its translation and intracellular stability," Molecular Cell, vol. 12, no. 3, pp. 591-601, 2003.

[249] J. S. Albin and R. S. Harris, "Interactions of host APOBEC3 restriction factors with HIV-1 in vivo: implications for therapeutics," Expert reviews in molecular medicine, vol. 12, articl e4, 2010.

[250] S. Kupzig, V. Korolchuk, R. Rollason, A. Sugden, A. Wilde, and G. Banting, "Bst-2/HM1.24 is a raft-associated apical membrane protein with an unusual topology," Traffic, vol. 4, no. 10, pp. 694$709,2003$.
[251] S. J. D. Neil, S. W. Eastman, N. Jouvenet, and P. D. Bieniasz, "HIV-1 vpu promotes release and prevents endocytosis of nascent retrovirus particles from the plasma membrane," PLoS pathogens, vol. 2, no. 5, article e39, 2006.

[252] N. Van Damme, D. Goff, C. Katsura et al., "The interferoninduced protein BST-2 restricts HIV-1 release and is downregulated from the cell surface by the viral vpu protein," Cell Host and Microbe, vol. 3, no. 4, pp. 245-252, 2008.

[253] N. Jouvenet, S. J. D. Neil, M. Zhadina et al., "Broad-spectrum inhibition of retroviral and filoviral particle release by tetherin," Journal of Virology, vol. 83, no. 4, pp. 1837-1844, 2009.

[254] P. Bates, R. L. Kaletsky, J. R. Francica, and C. Agrawal-Gamse, "Tetherin-mediated restriction of filovirus budding is antagonized by the Ebola glycoprotein," Proceedings of the National Academy of Sciences of the United States of America, vol. 106, no. 8, pp. 2886-2891, 2009.

[255] M. Mansouri, K. Viswanathan, J. L. Douglas et al., "Molecular mechanism of BST2/tetherin downregulation by K5/MIR2 of Kaposi's sarcoma-associated herpesvirus," Journal of Virology, vol. 83, no. 19, pp. 9672-9681, 2009.

[256] D. Perez-Caballero, T. Zang, A. Ebrahimi et al., "Tetherin inhibits HIV-1 release by directly tethering virions to cells," Cell, vol. 139, no. 3, pp. 499-511, 2009.

[257] M. Dubé, B. B. Roy, P. Guiot-Guillain et al., "Antagonism of tetherin restriction of HIV-1 release by vpu involves binding and sequestration of the restriction factor in a perinuclear compartment," PLoS pathogens, vol. 6, no. 4, p. e1000856, 2010.

[258] R. S. Mitchell, C. Katsura, M. A. Skasko et al., "Vpu antagonizes BST-2-mediated restriction of HIV-1 release via $\beta$-TrCP and endo-lysosomal trafficking," PLoS Pathogens, vol. 5, no. 5, Article ID e1000450, 2009.

[259] E. Bartee, A. McCormack, and K. Früh, "Quantitative membrane proteomics reveals new cellular targets of viral immune modulators," PLoS pathogens, vol. 2, no. 10, article e107, 2006.

[260] J. L. Douglas, K. Viswanathan, M. N. McCarroll, J. K. Gustin, K. Früh, and A. V. Moses, "Vpu directs the degradation of the human immunodeficiency virus restriction factor BST-2/tetherin via a $\beta$ TrCP-dependent mechanism," Journal of Virology, vol. 83, no. 16, pp. 7931-7947, 2009.

[261] E. Miyagi, A. J. Andrew, S. Kao, and K. Strebe, "Vpu enhances HIV-1 virus release in the absence of Bst-2 cell surface downmodulation and intracellular depletion," Proceedings of the National Academy of Sciences of the United States of America, vol. 106, no. 8, pp. 2868-2873, 2009.

[262] B. Jia, R. Serra-Moreno, W. Neidermyer Jr. et al., "Species-specific activity of SIV Nef and HIV-1 vpu in overcoming restriction by tetherin/BST2," PLoS Pathogens, vol. 5, no. 5, Article ID e1000429, 2009.

[263] F. Zhang, S. J. Wilson, W. C. Landford et al., "Nef proteins from simian immunodeficiency viruses are tetherin antagonists," Cell Host and Microbe, vol. 6, no. 1, pp. 54-67, 2009.

[264] R. K. Gupta, P. Mlcochova, A. Pelchen-Matthews et al., "Simian immunodeficiency virus envelope glycoprotein counteracts tetherin/BST-2/CD317 by intracellular sequestration," Proceedings of the National Academy of Sciences of the United States of America, vol. 106, no. 49, pp. 20889-20894, 2009.

[265] A. Le Tortorec and S. J. D. Neil, "Antagonism to and intracellular sequestration of human tetherin by the human immunodeficiency virus type 2 envelope glycoprotein," Journal of Virology, vol. 83, no. 22, pp. 11966-11978, 2009.

[266] D. Ayinde, C. Maudet, C. Transy, and F. Margottin-Goguet, "Limelight on two HIV/SIV accessory proteins in macrophage 
infection: is Vpx overshadowing Vpr?" Retrovirology, vol. 7, article 35, 2010.

[267] C. Goujon, L. Jarrosson-Wuillème, J. Bernaud, D. Rigal, J.-L. Darlix, and A. Cimarelli, "With a little help from a friend: increasing HIV transduction of monocyte-derived dendritic cells with virion-like particles of SIVMAC," Gene Therapy, vol. 13, no. 12, pp. 991-994, 2006.

[268] N. Sunseri, M. O’Brien, N. Bhardwaj, and N. R. Landau, "Human immunodeficiency virus type 1 modified to package Simian immunodeficiency virus Vpx efficiently infects macrophages and dendritic cells," Journal of virology, vol. 85, no. 13, pp. 6263-6274, 2011.

[269] M. Fujita, M. Otsuka, M. Miyoshi, B. Khamsri, M. Nomaguchi, and A. Adachi, "Vpx is critical for reverse transcription of the human immunodeficiency virus type 2 genome in macrophages," Journal of Virology, vol. 82, no. 15, pp. 7752-7756, 2008.

[270] K. Hrecka, C. Hao, M. Gierszewska et al., "Vpx relieves inhibition of HIV-1 infection of macrophages mediated by the SAMHD1 protein," Nature, vol. 474, no. 7353, pp. 658-661, 2011.

[271] N. Laguette, B. Sobhian, N. Casartelli et al., "SAMHD1 is the dendritic- and myeloid-cell-specific HIV-1 restriction factor counteracted by Vpx," Nature, vol. 474, no. 7353, pp. 654-657, 2011.

[272] S. Srivastava, S. K. Swanson, N. Manel, L. Florens, M. P. Washburn, and J. Skowronski, "Lentiviral Vpx accessory factor targets VprBP/DCAF1 substrate adaptor for cullin 4 E3 ubiquitin ligase to enable macrophage infection," PLoS Pathogens, vol. 4, no. 5, Article ID e1000059, 2008.

[273] A. Bergamaschi, D. Ayinde, A. David et al., "The human immunodeficiency virus type $2 \mathrm{Vpx}$ protein usurps the CUL4ADDB1DCAF1 ubiquitin ligase to overcome a postentry block in macrophage infection," Journal of Virology, vol. 83, no. 10, pp. 4854-4860, 2009.

[274] D. C. Goldstone, V. Ennis-Adeniran, J. J. Hedden et al., "HIV-1 restriction factor SAMHD1 is a deoxynucleoside triphosphate triphosphohydrolase," Nature, vol. 480, no. 7377, pp. 379-382, 2011.

[275] H. Lahouassa, W. Daddacha, H. Hofmann et al., "SAMHD1 restricts the replication of human immunodeficiency virus type 1 by depleting the intracellular pool of deoxynucleoside triphosphates," Nature Immunology, vol. 13, no. 3, pp. 223-228, 2012.

[276] A. Brandariz-Nunez, J. C. Valle-Casuso, T. E. White et al., "Role of samhd1 nuclear localization in restriction of hiv-1 and sivmac," Retrovirology, vol. 9, article 49, 2012.

[277] A. Goncalves, E. Karayel, G. I. Rice et al., "Samhd1 is a nucleic-acid binding protein that is mislocalized due to aicardi-goutieres syndrome-associated mutations," Human Mutation, vol. 33, pp. 1116-1122, 2012.

[278] G. I. Rice, J. Bond, A. Asipu et al., "Mutations involved in Aicardi-Goutières syndrome implicate SAMHD1 as regulator of the innate immune response," Nature Genetics, vol. 41, no. 7, pp. 829-832, 2009.

[279] A. Berger, A. F. R. Sommer, J. Zwarg et al., "SAMHD1-deficient $\mathrm{CD}_{1}{ }^{+}$cells from individuals with Aicardi-Goutières syndrome are highly susceptible to HIV-1 infection," PLoS Pathogens, vol. 7, no. 12, Article ID e1002425, 2011.

[280] N. Li, W. Zhang, and X. Cao, "Identification of human homologue of mouse IFN- $\gamma$ induced protein from human dendritic cells," Immunology Letters, vol. 74, no. 3, pp. 221-224, 2000.

[281] P. Blanco, A. K. Palucka, M. Gill, V. Pascual, and J. Banchereau, "Induction of dendritic cell differentiation by IFN- $\alpha$ in systemic lupus erythematosus," Science, vol. 294, no. 5546, pp. 1540-1543, 2001.

[282] S. M. Santini, C. Lapenta, M. Logozzi et al., "Type I interferon as a powerful adjuvant for monocyte-derived dendritic cell development and activity in vitro and in Hu-PBL-SCID mice," Journal of Experimental Medicine, vol. 191, no. 10, pp. 1777-1788, 2000.

[283] S. Gallucci, M. Lolkema, and P. Matzinger, "Natural adjuvants: endogenous activators of dendritic cells," Nature Medicine, vol. 5, no. 11, pp. 1249-1255, 1999.

[284] R. L. Paquette, N. C. Hsu, S. M. Kiertscher et al., "Interferon$\alpha$ and granulocyte-macrophage colony-stimulating factor differentiate peripheral blood monocytes into potent antigenpresenting cells," Journal of Leukocyte Biology, vol. 64, no. 3, pp. 358-367, 1998.

[285] A. C. Larner, E. F. Petricoin, Y. Nakagawa, and D. S. Finbloom, "IL-4 attenuates the transcriptional activation of both IFN- $\alpha$ and IFN- $\gamma$-induced cellular gene expression in monocytes and monocytic cell lines," Journal of Immunology, vol. 150, no. 5, pp. 1944-1950, 1993.

[286] C. Wang, H. M. Al-Omar, L. Radvanyi et al., "Clonal heterogeneity of dendritic cells derived from patients with chronic myeloid leukemia and enhancement of their T-cells stimulatory activity by IFN- $\alpha$," Experimental Hematology, vol. 27, no. 7, pp. 1176-1184, 1999.

[287] E. Padovan, G. C. Spagnoli, M. Ferrantini, and M. Heberer, "IFN- $\alpha 2$ a induces IP-10/CXCL10 and MIG/CXCL9 production in monocyte-derived dendritic cells and enhances their capacity to attract and stimulate $\mathrm{CD}^{+}$effector T cells," Journal of Leukocyte Biology, vol. 71, no. 4, pp. 669-676, 2002.

[288] F. Mattei, G. Schiavoni, F. Belardelli, and D. F. Tough, "IL-15 is expressed by dendritic cells in response to type I IFN, doublestranded RNA, or lipopolysaccharide and promotes dendritic cell activation," Journal of Immunology, vol. 167, no. 3, pp. 11791187, 2001.

[289] T. Ito, R. Amakawa, M. Inaba, S. Ikehara, K. Inaba, and S. Fukuhara, "Differential regulation of human blood dendritic cell subsets by IFNs," Journal of Immunology, vol. 166, no. 5, pp. 2961-2969, 2001.

[290] M. Lehner, T. Felzmann, K. Clodi, and W. Holter, “Type I interferons in combination with bacterial stimuli induce apoptosis of monocyte-derived dendritic cells," Blood, vol. 98, no. 3, pp. 736-742, 2001.

[291] M. B. Litinskiy, B. Nardelli, D. M. Hilbert et al., "DCs induce CD40-independent immunoglobulin class switching through BLyS and APRIL," Nature Immunology, vol. 3, no. 9, pp. 822829, 2002.

[292] B. L. McRae, R. T. Semnani, M. P. Hayes, and G. A. Van Seventer, "Type I IFNs inhibit human dendritic cell IL-12 production and Th1 cell development," Journal of Immunology, vol. 160, no. 9, pp. 4298-4304, 1998.

[293] E. J. Bartholomé, F. Willems, A. Crusiaux, K. Thielemans, L. Schandene, and M. Goldman, "IFN- $\beta$ interferes with the differentiation of dendritic cells from peripheral blood mononuclear cells: selective inhibition of CD40-dependent interleukin-12 secretion," Journal of Interferon and Cytokine Research, vol. 19, no. 5, pp. 471-478, 1999.

[294] B. L. McRae, B. A. Beilfuss, and G. A. Van Seventer, "IFN$\beta$ differentially regulates CD40-induced cytokine secretion by human dendritic cells," Journal of Immunology, vol. 164, no. 1, pp. 23-28, 2000. 
[295] P. Kaliński, J. H. N. Schuitemaker, C. M. U. Hilkens, E. A. Wierenga, and M. L. Kapsenberg, "Final maturation of dendritic cells is associated with impaired responsiveness to IFN- $\gamma$ and to bacterial IL-12 inducers: decreased ability of mature dendritic cells to produce IL-12 during the interaction with Th cells," Journal of Immunology, vol. 162, no. 6, pp. 3231-3236, 1999.

[296] A. Langenkamp, M. Messi, A. Lanzavecchia, and F. Sallusto, "Kinetics of dendritic cell activation: impact on priming of TH1,TH2 and nonpolarized T cells," Nature Immunology, vol. 1, no. 4, pp. 311-316, 2000.

[297] C. H. Kim and H. E. Broxmeyer, "Chemokines: signal lamps for trafficking of $\mathrm{T}$ and B cells for development and effector function," Journal of Leukocyte Biology, vol. 65, no. 1, pp. 6-15, 1999.

[298] S. Parlato, S. M. Santini, C. Lapenta et al., "Expression of CCR-7, MIP-3 $\beta$, and Th- 1 chemokines in type I IFN-induced monocyte-derived dendritic cells: importance for the rapid acquisition of potent migratory and functional activities," Blood, vol. 98, no. 10, pp. 3022-3029, 2001.

[299] S. J. Szabo, B. M. Sullivan, C. Sternmann, A. R. Satoskar, B. P. Sleckman, and L. H. Glimcher, "Distinct effects of T-bet in Th1 lineage commitment and IFN- $\gamma$ production in CD4 and CD8 T cells," Science, vol. 295, no. 5553, pp. 338-342, 2002.

[300] S. S. Cho, C. M. Bacon, C. Sudarshan et al., "Activation of STAT4 by IL-12 and IFN- $\alpha$ : evidence for the involvement of ligand-induced tyrosine and serine phosphorylation," Journal of Immunology, vol. 157, no. 11, pp. 4781-4789, 1996.

[301] L. Rogge, D. D’Ambrosio, M. Biffi et al., "The role of Stat4 in species-specific regulation of Th cell development by type I IFNs," Journal of Immunology, vol. 161, no. 12, pp. 6567-6574, 1998.

[302] L. S. Berenson, J. D. Farrar, T. L. Murphy, and K. M. Murphy, "Frontline: absence of functional STAT4 activation despite detectable tyrosine phosphorylation induced by murine IFN- $\alpha$," European Journal of Immunology, vol. 34, no. 9, pp. 2365-2374, 2004.

[303] L. S. Berenson, M. Gavrieli, J. D. Farrar, T. L. Murphy, and K. M. Murphy, "Distinct characteristics of murine STAT4 activation in response to IL-12 and IFN- $\alpha$," Journal of Immunology, vol. 177, no. 8, pp. 5195-5203, 2006.

[304] J. P. Huber and J. David Farrar, "Regulation of effector and memory T-cell functions by type I interferon," Immunology, vol. 132, no. 4, pp. 466-474, 2011.

[305] S. Matikainen, A. Paananen, M. Miettinen et al., "Ifn-alpha and il-18 synergistically enhance ifn-gamma production in human nk cells: differential regulation of stat 4 activation and ifn-gamma gene expression by ifn-alpha and il-12," European Journal of Immunology, vol. 31, pp. 2236-2245, 2001.

[306] M. Strengell, I. Julkunen, and S. Matikainen, "IFN- $\alpha$ regulates IL-21 and IL-21R expression in human NK and T cells," Journal of Leukocyte Biology, vol. 76, no. 2, pp. 416-422, 2004.

[307] L. E. Harrington, R. D. Hatton, P. R. Mangan et al., "Interleukin 17-producing $\mathrm{CD}^{+}$effector T cells develop via a lineage distinct from the T helper type 1 and 2 lineages," Nature Immunology, vol. 6, no. 11, pp. 1123-1132, 2005.

[308] A. R. Moschen, S. Geiger, I. Krehan, A. Kaser, and H. Tilg, "Interferon-alpha controls IL-17 expression in vitro and in vivo," Immunobiology, vol. 213, no. 9-10, pp. 779-787, 2008.

[309] L. J. Thompson, G. A. Kolumam, S. Thomas, and K. Murali-Krishna, "Innate inflammatory signals induced by various pathogens differentially dictate the IFN-I dependence of CD8 T cells for clonal expansion and memory formation," Journal of Immunology, vol. 177, no. 3, pp. 1746-1754, 2006.
[310] G. A. Kolumam, S. Thomas, L. J. Thompson, J. Sprent, and K. Murali-Krishna, "Type I interferons act directly on CD8 T cells to allow clonal expansion and memory formation in response to viral infection," Journal of Experimental Medicine, vol. 202, no. 5, pp. 637-650, 2005.

[311] J. M. Curtsinger, J. O. Valenzuela, P. Agarwal, D. Lins, and M. F. Mescher, "Cutting edge: type I IFNs provide a third signal to CD8 T cells to stimulate clonal expansion and differentiation," Journal of Immunology, vol. 174, no. 8, pp. 4465-4469, 2005. 


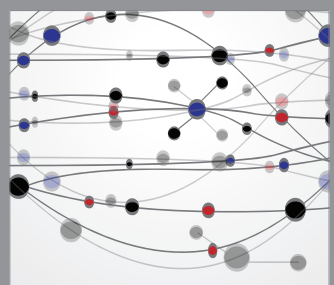

The Scientific World Journal
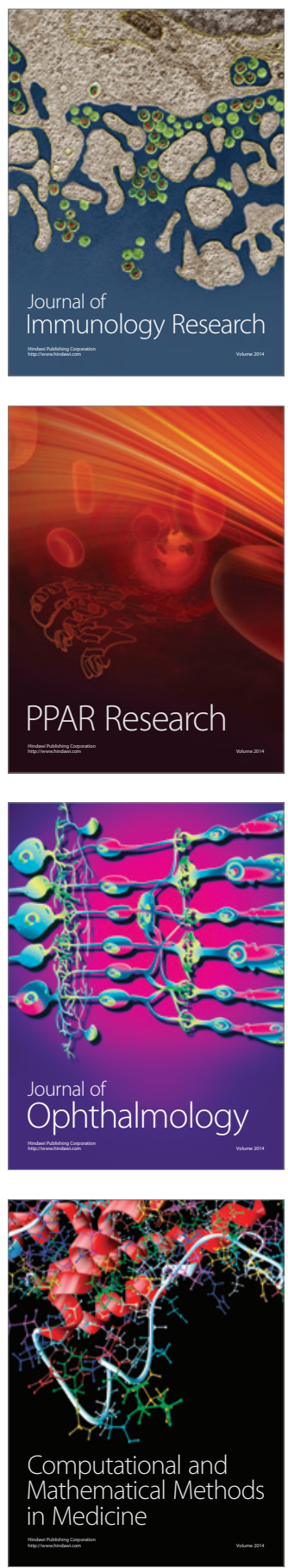

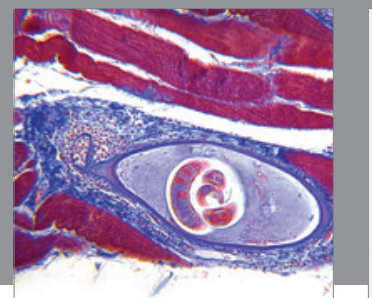

Gastroenterology

Research and Practice
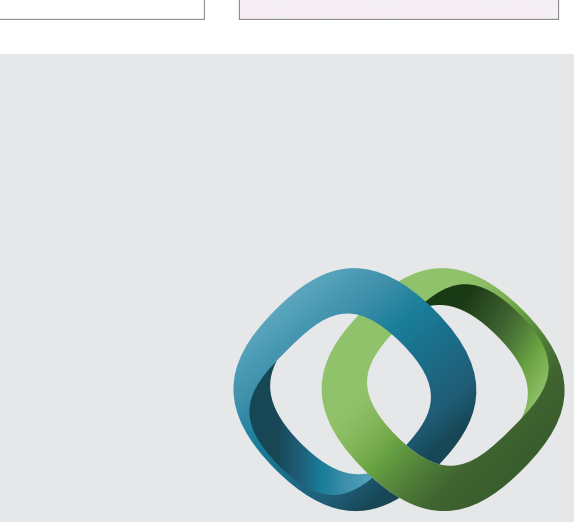

\section{Hindawi}

Submit your manuscripts at

http://www.hindawi.com
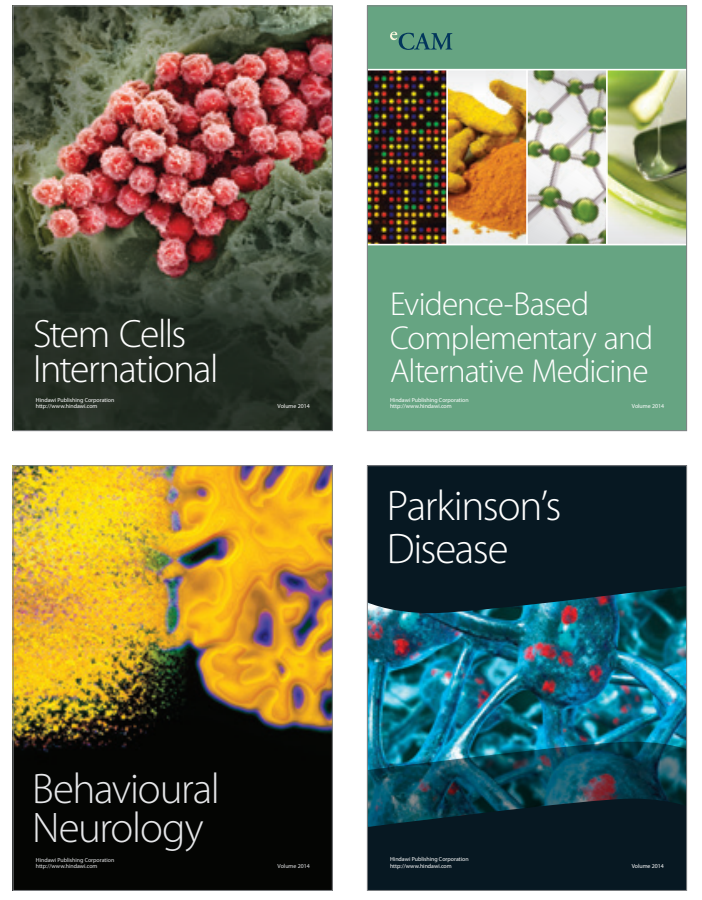
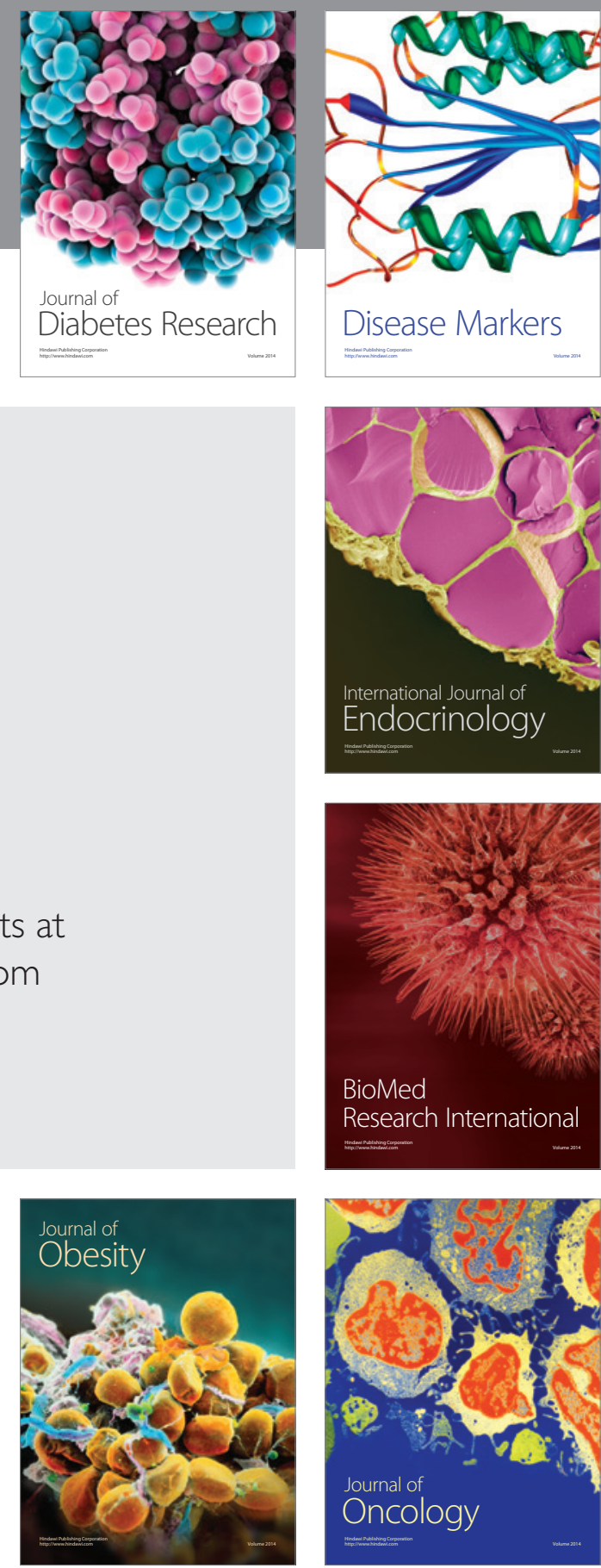

Disease Markers
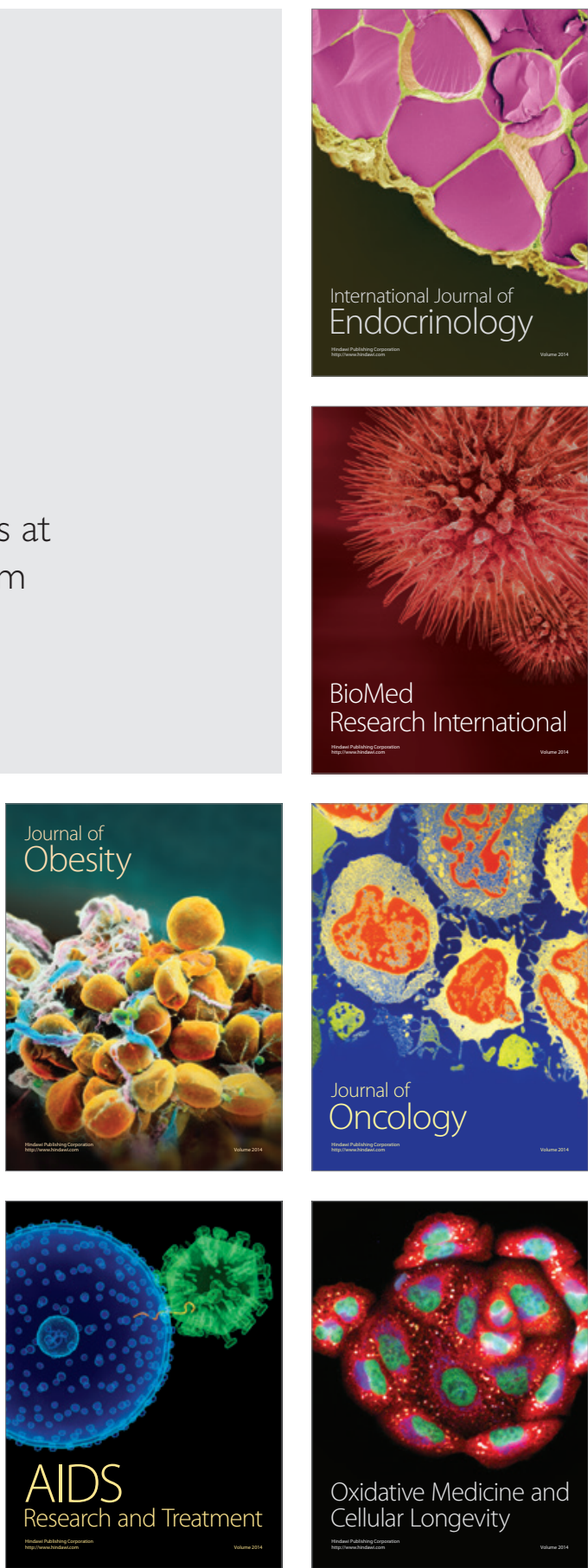